\title{
NBSIR 84-2974
}

\section{CEL-1 User's Guide Update}

\author{
S. Treado \\ C. Francisco \\ D. Holland
}

U.S. DEPARTMENT OF COMMERCE

National Bureau of Standards

National Engineering Laboratory

Center for Building Technology

Gaithersburg, MD 20899

William Pierpoint

Naval Civil Engineering Laboratory

Port Hueneme, CA 93043

November 1984

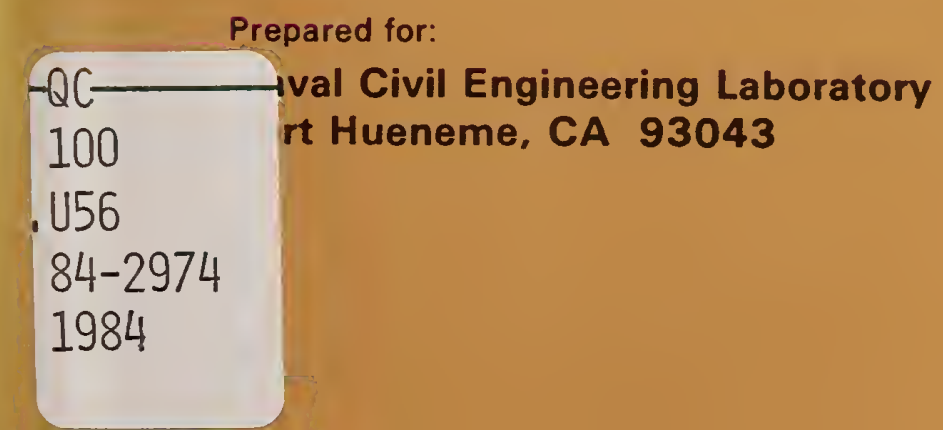





\section{CEL-1 USER'S GUIDE UPDATE}
S. Treado
C. Francisco
D. Holland

U.S. DEPARTMENT OF COMMERCE

National Bureau of Standards

National Engineering Laboratory

Center for Building Technology

Gaithersburg, MD 20899

William Pierpoint

Naval Civil Engineering Laboratory

Port Hueneme, CA 93043

November 1984

Prepared for:

Naval Civil Engineering Laboratory

Port Hueneme, CA 93043

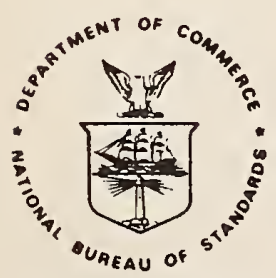

U.S. DEPARTMENT OF COMMERCE, Malcolm Baldrige, Secretary NATIONAL BUREAU OF STANDARDS. Ernest Ambler, Director 



\section{ABSTRACT}

This is a guide to using the CEI-1.1 version of the CEL-1 Lighting Computer Program. CEL-1.1 has the capability of producing hour-by-hour lighting power multipliers for a one-year simulation period. This guide focuses on:
a) the new program routines
b) the interactive capabilities of CEL-1.1
c) the procedures for compiling different types of routines
d) computer terminology and accessing the necessary routines for running CEL-1.1
e) updates and revisions to the existing CEL-1 manuals

Key words: BLAST generator, cloud ratio, direct and diffuse illuminance, direct and diffuse irradiance, lighting power multipliers 
FORWORD

This report documents the results of National Bureau of Standards (NBS) research in support of the Naval Civil Engineering Laboratory. The report summarizes work conducted during the period January 1983 through October 1983.

\section{DISCLAIMER}

Certain commercial equipment, instruments, or materials are identified in this report to specify the experimental procedure. Such identification does not imply that the materials or equipment identified are necessarily the best available for the purpose.

ACKNOWLEDGEMENTS

The authors wish to acknowledge the efforts of all those who participated in this project and who provided insightful comments during the review process. 


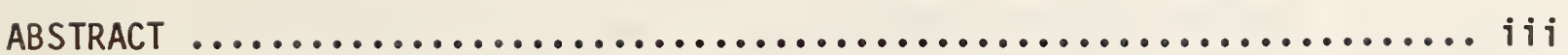

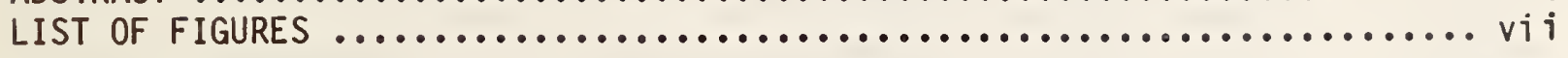

1. INTRODUCTION ........................................ 1

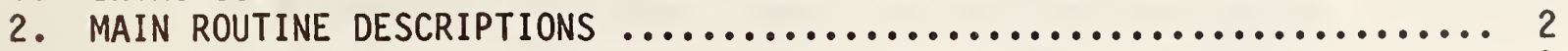

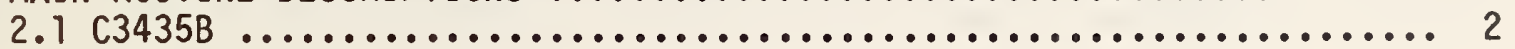

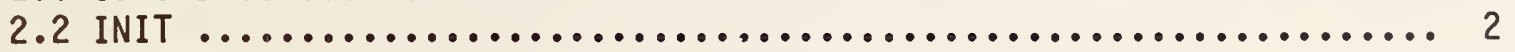

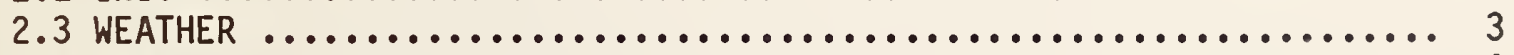

2.4 LOOP .................................................. 4

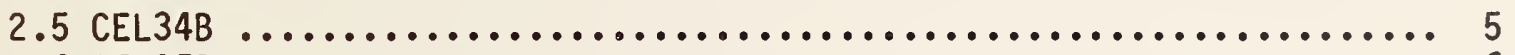

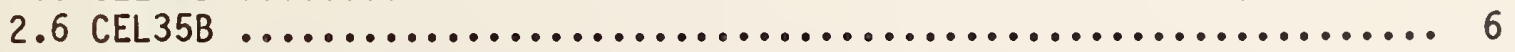

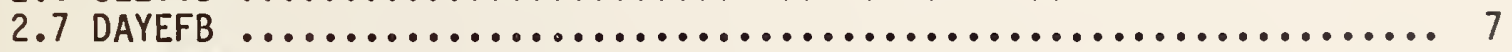

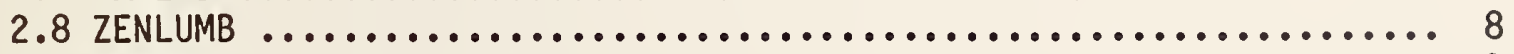

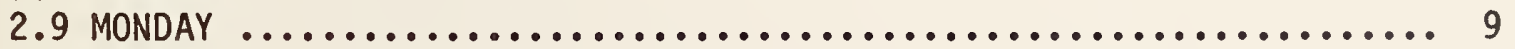

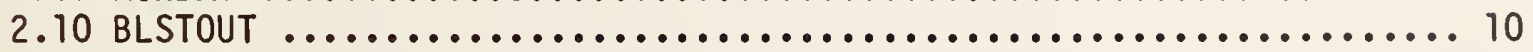

2.11 CEL -1 ............................................... 10

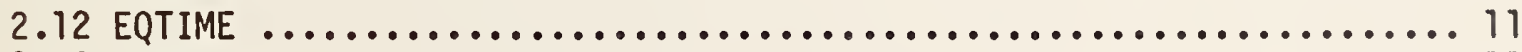

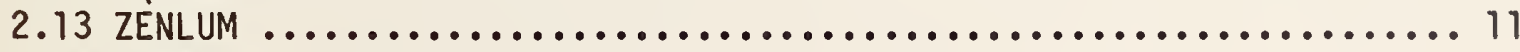

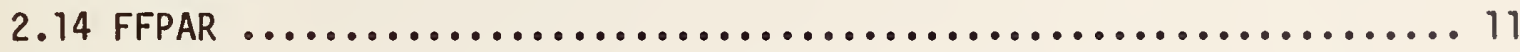

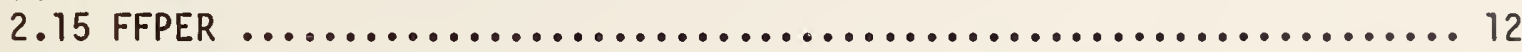

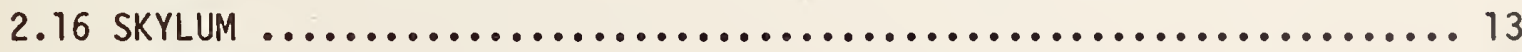

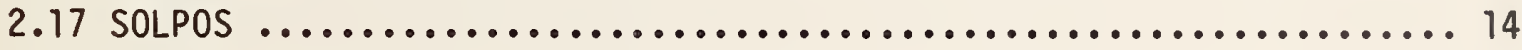

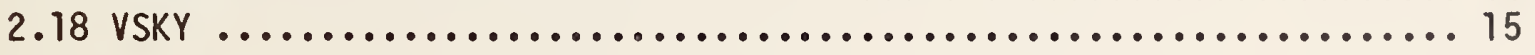

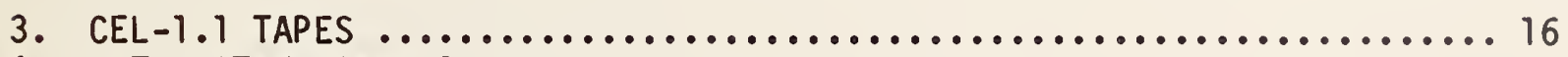

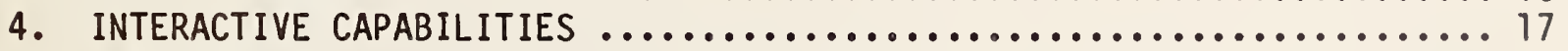

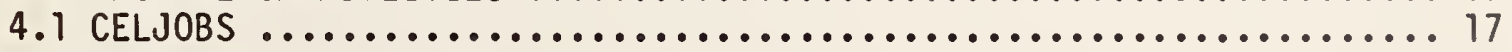

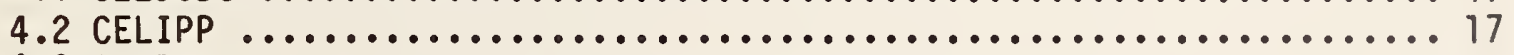

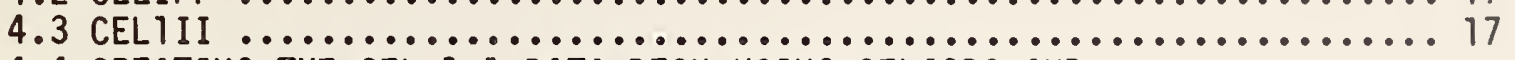

4.4 CREATING THE CEL-1.1 DATA DECK USING CELJOBS AND

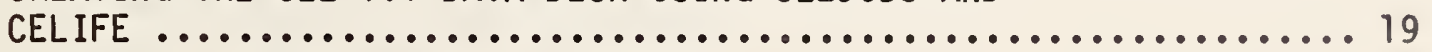

4.5 CREATING A BATCH JOB USING CELJOBS ......................... 24

4.6 SUBMITTING THE CEL-1.1 DATA DECK USING CELJOBS AND

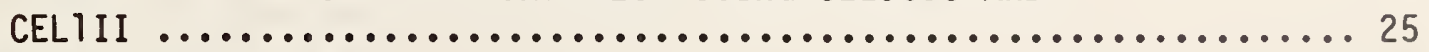

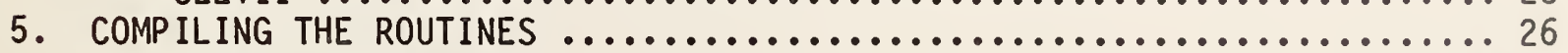

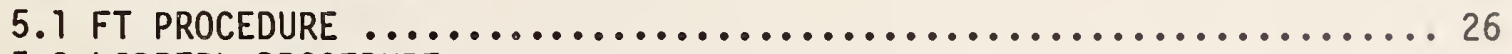

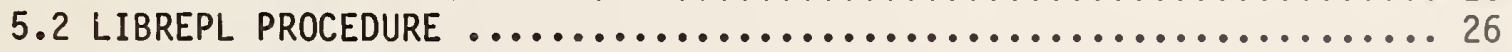

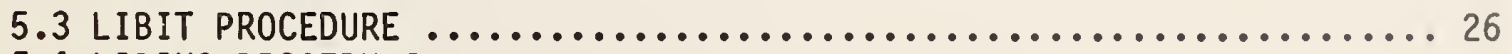

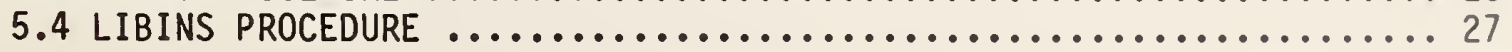

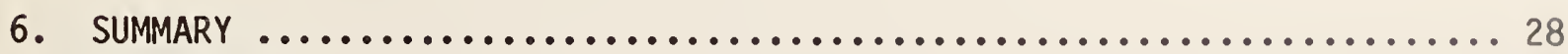

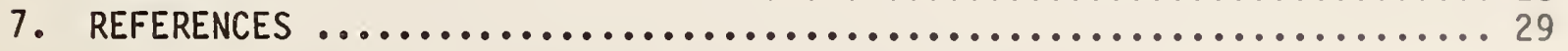

APPENDIX A. COMPUTER TERMINOLOGY AND SYMBOLS FOR BOEING

COMPUTER SYSTEM ................................ 33

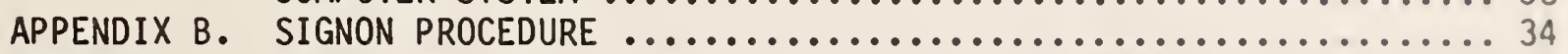

APPENDIX C. ACCESSING CELJOBS AND RELATED COMPUTER COMMANDS ........ 35

APPENDIX D. NECESSARY FILES FOR RUNNING CELJOBS $\ldots \ldots \ldots \ldots \ldots \ldots \ldots \ldots$ 
APPENDIX E. COMMON BLOCK VARIABLE DEFINITIONS ................ 37

APPENDIX $F$. LOGICAL UNIT ASSIGNMENTS $\ldots \ldots \ldots \ldots \ldots \ldots \ldots \ldots \ldots \ldots \ldots \ldots \ldots \ldots \ldots$

APPENDIX G. PROGRAM CALLING SEQUENCE TREE .................... 39

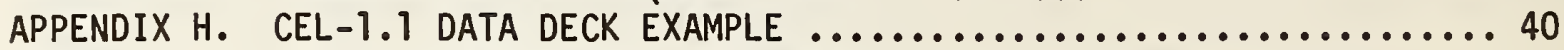

APPENDIX I. BLAST SCHEDULE OUTPUT EXAMPLE .................... 42

APPENDIX J. REVISIONS FOR THE CEL-1 USER'S GUIDE AND PROGRAMMER'S GUIDE 


\section{LIST OF FIGURES}

$\underline{\text { Page }}$

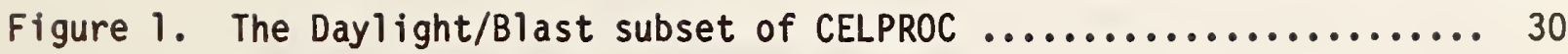

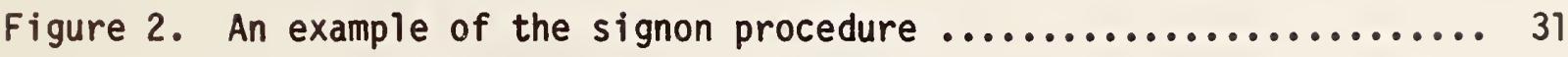

Figure 3. Room Layout for CEL-1.1 example data deck .............. 32 



\section{INTRODUCTION}

CEL-1.1 is an updated version of the CEL-1 lighting computer program. The modifications include the use of weather data in the daylighting subset of the program and the capability of a one-year simulation. The weather data consist of diffuse and direct irradiance values which are used to generate the illuminance values. These values are used to produce hour-by-hour lighting power fractions which are output in the form of BLAST lighting Schedules and LIGHTS statements.

CEL-1 Lighting Computer Program was designed to be used as an aid to engineers in the designing of energy efficient buildings. CEL-1 has three subsets which are:
1) Electric Light subset
2) Daylight subset
3) Partition/Synthesis subset

The Electric Light subset is designed to compute $i l l$ uminance at a large number of target locations. The Daylight subset performs daylight calculations for more than one condition. The Partition/Synthesis subset is used when the design synthesizer is called and furniture is in the room.

With the updated version there is a fourth subset which is used whenever daylighting calculations and BLAST lighting Schedules are needed. This subset is designed for profile mode. The Daylight/BLAST subset is shown in the shaded portion of figure 1 .

This paper should be used as a guide to running CEL-1.1. The user should be familiar with the terminology and the procedures of CEL-1 before using CEL-1.1. See the reference list at the end of this report for information on existing CEL-1 manuals. Section 2 describes the main program routines, including updates and changes. Sections 3 and 4 cover the use of tapes and interactive capabilities. Section 5 contains information about compiling the program routines. Appendices A through $D$ describe how to access the Boeing Computer System and execute CEL-1.1 Appendices $E$ through $G$ cover technical information internal to CELI. A sample CEL-1 data deck is shown in Appendix $H$ and the related output is listed in Appendix I. Revisions to the CEL-I User's and Programmers Guides are contained in Appendix $J$. 
2. MAIN ROUTINE DESCRIPTIONS

\section{$2.1 \quad$ C $3435 B$}

\section{Purpose}

Program C3435B directs the calls to the subroutines which are used for the weather data input and the BLAST Lighting Schedules output.

Method

1) Checks to see if the BLAST Lighting Schedules run has been requested.

2) Calls the necessary routines for the weather data input and the BLAST Lighting Schedules run.

\subsection{INIT}

\section{Purpose}

Subroutine INIT initializes the variables which control the number of repetitons of CEL34B and CEL35B.INIT checks the weather data file for errors and reads the data.

\section{Method}

1) The data is read from binary disc files.

2) The variables are initialized.

3) Checks for the weather data file and gives an error message if it is not available.

4) Reads the weather file title data and gives an error message if it is incorrect.

5) Reads the weather data until the first day is found.

6) The data is passed to the other routines by the common block /DATA/.

\section{Variables/Arrays}

LUDAY - logical unit \#32, latitude, longitude, occupancy factors, etc.

LUBAS - logical unit \#3, common block /COBAS/

LUBS - logical unit \#95, initial values for DY1, FRSTDY, LSTDY

HBLST - keyword for the BLAST Lighting Schedule generator, HBLST $=1$ then BLAST generator is run

WTHRFL - weather data file

WFSDAY - starting day of the weather data file

DAYYR - day of the year for one record on the weather file

WFEDAY - ending day of the weather file 
Note: All the other variables in the common blocks, which are not defined in this manual, are not used by CEL-1.1. They are there for the convenience of the programmer.

\subsection{WEATHER}

\section{Purpose}

SUbroutine WEATHER reads diffuse irradiance and direct irradiance. It converts the data into diffuse horizontal illuminance, direct horizontal illuminance, and cloud ratio. This data is stored on disc LUWEA, one record per day.

Method

1) Direct and diffuse irradiance are read from WTHRFL.

2) Diffuse horizontal illuminance is calculated according to the following equation:

$$
E_{d}=119 \times I_{d}
$$

where $\quad E_{d}=$ diffuse horizontal illuminance (lux)

Id $=$ diffuse horizontal irradiance $\left(\mathrm{Wm}^{-2}\right)$
IIg = luminous efficacy for diffuse illumination (lumens/watt) [1].

3) Direct horizontal illuminance is calculated using the following relation:

$$
E_{D}=E_{T}-E_{d}
$$

where $E_{D}=$ direct horizontal illuminance (lux)

$E_{T}=$ total horizontal illuminance (lux) [1].

Total illuminance is calculated using the following equation:

$$
E_{T}=\left(105 \times I_{T}\right)+\left(14 \times I_{d}\right)
$$

where $I_{I}=$ total irradiance $\left(\mathrm{Wm}^{-2}\right)$

$105=$ the luminous efficacy for direct irradiance (lumens/watt) [1].

Total irradiance is calculated using the following equation:

$$
I_{T}=I_{d}+\left(I_{D N} \times \sin h\right)
$$

where $\begin{aligned} I_{D N} & =\text { direct normal irradiance }\left(W^{-2}\right) \\ h & =\text { solar elevation. }\end{aligned}$

4) Cloud ratio is calculated according to the following equation:

$$
C R=\frac{I_{d}}{I_{T}}
$$


where $\quad C R=$ cloud ratio $[1]$.

5) Direct and diffuse illuminance and cloud ratio are written to disc. There is one record for each day which contains 24 hours of data. This comprises the array WEA.

Variables/Arrays

LUWEA - logical unit 96, contains the processed weather data (illuminances and cloud ratio)

WTHRFL - logical unit 97, unprocessed irradiance data from BLAST weather tape

DY - julian day

HR - hour

IDIF - diffuse irradiance

IDIR - direct irradiance

ITOT - total irradiance

ETOT - total illuminance

TIM - converts HR to a real number

ELEV - solar elevation

AZ - solar azimuth

WEA - 3X24 array containing cloud ratio, diffuse and direct illuminance for 24 hours a day

ENVDAT - common block containing weather data from BLAST weather tapes

\section{$2.4 \quad \underline{L O O P}$}

\section{Purpose}

Subroutine LOOP calls CEL $34 B$ and CEL35B repeatedly depending on the number of days requested. Calculations are done in groups of three days. Each time through the $100 p$, new $i l l$ uminance data and cloud ratio data are supplied. The illuminance values are no longer supplied by HFCSUN and HFCSKY. Instead, parts of the code from these subroutines have been included in the code of DAYEFB, ZENLUMB, and CEL34B.

Method

1) The processed weather data is read from LUWEA.

2) Checks for non-working days and keeps checking the days until there is a working day.

3) Selects five hours during the working day symetric about solar noon, and then interpolates the weather data for those hours.

4) The weather data is stored in EDIF, EDIR, and CR accordingly. Each of these is a linear array of 15 elements with hours 1 thru 5 in the first day calculated, hours 6 thru 10 in the second day calculated, and hours 11 thru 15 in the third day. This data is in the common block/WEATH/. 
5) Checks for the last day requested in the run and repeats the last day, if necessary, to fill the data arrays so they contain three days of data.

6) Calls CEL34B and CEL35B.

7) Checks to make sure all the requested days have been processed.

\section{Vàriables/Arrays}

DY - Julian day

NDY - counter for creating the block of three days

DYINDX - the index for the starting element of the first hour of each day in the data arrays (index values $=1,6,11$ )

HRI - hour

\subsection{CEL34B}

\section{Purpose}

This subroutine is a modified version of CEL034 from the original CEL-1. CEL34B generates the daylight effects for all the times for which daylight calculations are needed.

\section{Method}

1) Read in the already computed values from disc.

2) Convert local time to solar time and compute solar position.

3) Cloud ratio is used to choose the sky condition. If CR is less than or equal to 0.2 , then it is clear. If the $C R$ is greater than 0.2 and less than or equal to 0.8 , then it is partly cloudy. If $C R$ is greater than 0.8 , then it is overcast.

4) If it is overcast, calculate the effect of unit luminance for an overcast sky. Factor the unit luminance values and write them to disc. Refer to sections 3.7 and 3.8 for a further explanation of these calculations.

5) It it is clear or partly cloudy, calculate the daylight effect and then add the solar component. In the original CELO34, HFCSUN calculated the solar component. CEL34B directly uses values for direct 111 uminance instead of calling HFCSUN. Since the illuminance values are in lux on the weather file, the conversion to footcandles is done here. Write the values to disc. Refer to sections 3.7 and 3.8 for further explanation of the daylight calculations.

Variables/Arrays

$$
\begin{aligned}
& \text { EDIR - direct illuminance } \\
& \text { CR - cloud ratio } \\
& \text { TT - solar time } \\
& \text { SUNAZ - solar azimuth }
\end{aligned}
$$


SUNEL - solar elevation

ZLUM - zenith luminance

HSUN - horizontal illuminance due to the sun

\subsection{CEL35B}

\section{Purpose}

This subroutine is a modified version of CEL035 from the original CEL-1. CEL35B generates the energy profile (lighting power multipliers) for daylight-affected lighting systems. It has been modified to select the sky condition according to the cloud ratio and it runs only once for each sky condition.

Method

1) Read in previously computed values from disc.

2) Establish the ID of each luminaire's photometry.

3) Determine the first and last hour of building occupancy.

4) Adjust array LGRP if luminaires are controlled individually. This will make the number of dimming groups equal to the number of luminaires.

5) The luminaires to be dimmed are grouped together.

6) To minimize the disc accesses required during the profile calculations, CMPRES is call ed [2].

7) The total possible watts consumed is computed and the quadratic coefficients are adjusted if dimming is not continuous.

8) The energy consumed by the luminaires with no daylight present is calculated. The result is the energy consumption before sunrise and after sunset.

9) For each time, gain settings are calculated by MSTRSN [2].

10) Cloud ratio is used to choose the sky condition in the same manner as in CEL34B.

11) Check for the last day. If it is the last day, read the contribution from disc and call MSTRSN to calculate the gain settings for each time instance.

12) If it is not the last day, set the gains to zero at the start of the next new day. Continue the same as above in Step 11.

13) Compute the hourly profile for each day for which calculations were made.

14) Use the osculating polynomial coefficients to get the hourly energy for a particular day (OCSU) [2]. 
15) Write the energy profile consumption (lighting power multipliers) for each day and hour to disc (LULPM).

Variables/Arrays

LULUM - logical unit \#13, luminaire locations and orientations

LUKTL - logical unit \#29, defines the array of target point coordinates, viewing directions, etc.

LUSURF - logical unit \#31, exterior building and ground surface definitions

LUDIM - logical unit \#19, parameters for luminaire control/energy profile

LUSEN - logical unit \#20, sensor definitions: locations, orientations

LUDAY - logical unit \#32, latitude, longitude, occupancy factors, etc.

LUBAS - logical unit \#8, common block/COBAS/

NLUM - \# of luminaires

NFOTO - the $\#$ of different photometric files used

OCCUP - the occupancy factor for a particular hour

NCONTR - the \# of controlled luminaires

INDW - an array which associates the luminaires with quadratic coefficients giving watts vs. gains

LUCONT - logical unit \#25, the contribution from each luminaire to the target points, the area points, and the sensors

NINSEN - the \# of interior sensors

NCTAPS - the $\#$ of area points

NTAR - the \# of target points

INRECD - indicator of which disc record is currently in memory

TOTALW - the total watts from the controlled luminaires

ALWAYS - the watts from the iuminaires always being on

LUDEF - logical unit \#45, daylight effects for each time instant

LGRP - the array which identifies the dimming group each luminaire belongs to; all luminaires with the same gain must be in one dimming group

WUSE - the watts consumption for each day and hour (array)

EN - an array containing 3 days and the hourly energy consumption

$\mathrm{EE}$ - the energy consumption for the controlled luminaires

OUT - the energy profile consumption for each day and hour (lighting power multipliers)

\subsection{DAYEFB}

\section{Purpose}

Subroutine DAYEFB is a modified version of the original DAYEF from CEL-1. It computes the total daylight effect on all target points, area points, and sensors depending on the sky condition which is chosen in CEL34B.

Method

1) Call TRIGS to compute the trigonometric functions of solar azimuth and solar elevation [2].

2) Call ZENLUMB to calculate zenith ruminance. 
3) If it is overcast, then the zenith luminance value is 1000.

4) Compute the horizontal solar illuminance on the earth due to the direct sunlight. If it is overcast, set the value to zero. Calculate the horizontal illuminance on the earth due to the unobstructed sky. If it is overcast, then set the value for the illuminance to 777.778. The illuminance values are converted from lux to footcandles since the weather data is in metric units and CEL-1.l uses english units.

5) From this point on, the calculations are the same as the original DAYEF [2].

\section{Variables/Arrays}

ISKY - sky condition: 1 = overcast, 2 = clear, 3 = partly cloudy

TIME - solar time

LUPRO - logical unit \#41, prototype FCTs

LU48 - logical unit $\# 48$, destination of 48 -ray projections from the target points

LUFCTS - logical unit \#16, FCTs on interior surface, sensors, area points

LUZONE - logical unit \#15, zonal multipliers for 48-ray projections

LUFTM - logical unit \#22, flux transfer matrix

LUSLUM - logical unit \#42, relative initial illuminance on the room surfaces due to fenestration

\subsection{ZENLUMB}

\section{Purpose}

Subroutine ZENLUMB generates the zenith luminance depending on the cloud ratio. It is a modified version of the original ZENLUM.

Method

1) Compute the horizontal illuminance on the earth due to the unobstructed sky. Refer to section 2.7 - step 4 for a further explanation. 
2) If the sky condition is overcast, then the zenith luminance is calculated by:

$$
Z L=9 / 7 \times F C
$$

where $\mathrm{ZL}=$ zenith luminance

$F C=$ horizontal sky illuminance [2].

3) If the sky condition is clear or partly cloudy, then the zenith luminance is calculated by:

$$
Z L=F C / Z
$$

where $\mathrm{ZL}=$ zenith luminance

$\mathrm{FC}=$ horizontal sky illuminance

$Z$ = obtained from the implied fixed relationship between the horizontal sky illuminance and the zenith luminance [2].

Variables/Arrays

ISKY -1 = overcast, 2 = clear, 3 = partly cloudy

NX - counter for the number of times (1 to 15)

ICOND - atmospheric condition indicator not used at this time

\subsection{MONDAY}

\section{Purpose}

Subroutine MONDAY converts the julian date into a three letter abbreviation for the name of the month. It generates the number of the month and the number of the day of the month.

\section{Method}

1) Compares the julian date with the julian date of the last day of the month. This process will choose the correct three letter abbreviation.

2) Determines the number of the day of the month.

\section{$\underline{\text { Variables/Array }}$}

MN - the number of the month (1 to 12)

JDAY - julian date (1 to 366)

MON - contains the ending julian date for each month

MONMM - contains the three letter abbreviations for the names of the months

DAYMON - the number of the day of the month ( 1 to 31)

MONTH - single element of the array MONNM 


\subsection{BLSTOUT}

\section{Purpose}

BLSTOUT creates a BLAST Lighting Schedule and LIGHTS statement to reference the lighting schedule. Each schedule contains a whole week of lighting power multipliers. The schedules are from Sunday to Saturday. The subroutine fills the schedules for weekends and days outside of the requested range with zero lighting power multipliers. This is to make a full week of schedules.

Method

1) Read the lighting power multipliers from disc LULPM.

2) Calculate the julian date for the Sunday of the first week.

3) Calculate the number of weeks of schedules to output.

4) Write the title information.

5) Check for non-working day. If it is a non-working day, then write the lighting power multipliers for the day as all zeros.

6) Otherwise, if it is a working day, write the BLAST Lighting Schedule for the day.

7) Write the LIGHTS statements for each week.

Variables/Arrays

NW - the number of the week for the BLAST schedule, it ranges from 1 to the number of weeks requested.

ND - the number of the day of the week ( 1 to 7 )

DY - the julian date

LSTWK - last week requested

DAYNAM - an array of literal names of the days of the week

MON - a literal name of a month

$M \quad$ - number of the month (1 to 12)

D - the number of the day of the month (1 to 31)

KTWATT - total watts in kilowatts

\subsection{CELO1}

Purpose

CELO1 reads the data deck and stores the data on binary disc files which can be used throughout the program. 
Method

CELO1 has been modified to read the additional data, from the data deck, for the BLAST Lighting Schedule generator. This data includes:

- the julian date of the first Saturday of the year,

- the julian dates of the first and last days of the generator run,

- the "BLS" key for the Calculate block [3].

This data is stored on a disc file, LUBS (logical unit \#95).

\subsection{EQTIME}

\section{Purpose}

EQTIME calculates the equation of time. This equation for time accounts for variations between solar time and clocked time due to two factors:

(1) the elliptical orbit of the earth and

(2) the solar declination of the axis.

\section{Method}

The equation of time is calculated using the following relation:

$$
E T=170 \times \sin \frac{4 \pi}{373}(J-80)-1.29 \times \sin \frac{2 \pi}{355}(J-8)
$$

$$
\text { where } \begin{aligned}
E T & =\text { equation of time (decimal hours) } \\
J & =\text { julian data }(1 \leqslant J \leqslant 365)[7] .
\end{aligned}
$$

\subsection{ZENLUM}

\section{Purpose}

ZENLUM computes the zenith luminance for given sky conditions. It has been modified to include values of $Z$ for solar altitudes from $0^{\circ}$ to $90^{\circ}$ in steps of $5^{\circ}$.

\section{Method}

The same as the original ZENLUM [2].

\subsection{FFPAR}

\section{Purpose}

The purpose of FFPAR is the same as the original. Refer to the CEL-1 Programmer's Guide for a further explanation [2]. 
Method

1) The form factor between two parallel surfaces is given by:

$$
F_{12}=\frac{Z^{2}}{2 \pi} A_{1}^{2} \sum_{i=1}^{2} \sum_{j=1}^{2} \sum_{k=1}^{2} \sum_{m=1}^{2} H\left(U_{i}, V_{j}, X_{k}, Y_{m}\right)(-1)^{i+j+K+m}
$$

where

$$
\begin{aligned}
& H\left(U_{i}, V_{j}, X_{K}, Y_{m}\right)=b V\left(1+a^{2}\right) \tan ^{-1} \frac{b}{\sqrt{1+a^{2}}}+a V\left(1+b^{2}\right) \tan ^{-1} \frac{a}{\sqrt{\left(1+b^{2}\right)}} \\
& \quad-1 / 2 \ln \left(1+a^{2}+b^{2}\right) \\
& a=\frac{1}{2}\left(X_{K}-U_{i}\right) \\
& b=\frac{1}{2}\left(Y_{m}-V_{j}\right) \\
& A 1=\text { area of surface } 1=\left(Y_{2}-Y_{1}\right)\left(X_{2}-X_{1}\right) .
\end{aligned}
$$

Variables/Arrays

$X 1, X_{2}-X-s p a n$ of the source surface

$Y 1, Y 2$ - Y-span of the source surface

$X 3, X 4$ - X-span of the receiving surface

$Y 3, Y 4$ - Y-span of the receiving surface

$Z$ - distance between the two surfaces

\subsection{FFPER}

\section{Purpose}

The same as the original FFPER. Refer to the CEL-1 Programmer's Guide [2].

\section{Method}

1) The form factor between two perpendicular surfaces is given by:

$$
F_{12}=\frac{1}{2 \pi A_{1}} \sum_{i=1}^{2} \sum_{j=1}^{2} \sum_{k=1}^{2} \underset{m=1}{2} G\left(V_{i}, Z_{j}, X_{k}, Y_{m}\right)(-1)^{i+j+k+m}
$$

where

$$
G\left(V_{i}, Z_{j}, X_{k}, Y_{m}\right)=a v\left(b^{2}+c^{2}\right) \tan ^{-1} \frac{a}{v\left(b^{2}+c^{2}\right)}+\frac{1}{4}\left(a^{2}-b^{2}-c^{2}\right) \times \ln \left(a^{2}+b^{2}+c^{2}\right)
$$




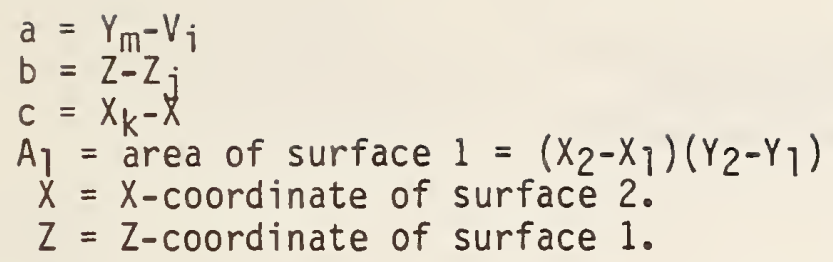

Variables/Arrays
$A 1, B 1$ - Y-span of the source surface
$C 1, D 1$ - X-span of the source surface
C2,D2 - Z-span of the receiving surface
$A 2, B 2$ - Y-span of the receiving surface

\subsection{SKYLUM}

\section{Purpose}

The purpose of SKYLUM is the same as the original SKYLUM. The calculations for the three sky types are different from the original.

Method

1) The clear sky luminance distribution is given:

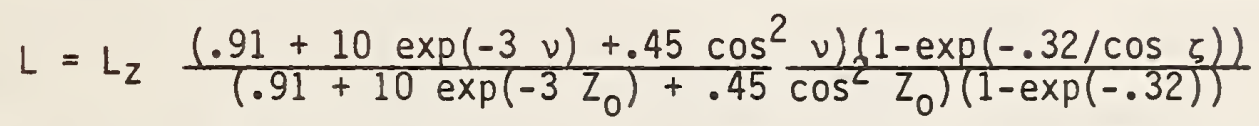

where $L=$ sky luminance at point $P$

$L_{z}=$ sky zenith luminance

$\nu=$ angle between the sun and sky point $P$

$\zeta=$ zenith point angle

$Z_{0}=$ zenithal sun angle $[7]$.

2) The partly cloudy sky luminance distribution is calculated by:

$$
L=L_{z} \frac{(.526+5 \exp (-1.5 v))(1-\exp (-.80 / \cos \zeta))}{\left(.526+5 \exp \left(-1.5 Z_{0}\right)\right)(1-\exp (-.80))}
$$

where $L=$ sky luminance at point $P$

$L_{z}=$ sky zenith luminance

$v=$ angle between the sun and sky point $P$

$\zeta=$ zenithal point angle

$Z_{0}=$ zenithal sun angle [7].

3) The overcast sky luminance model is given by:

$$
L=\frac{L_{z}}{3}(1+2 \cos \zeta)
$$




$$
\text { where } \begin{aligned}
L & =\text { sky luminance at point } P \\
L_{z} & =\text { sky zenith luminance } \\
\zeta & =\text { zenithal point angle }[7] .
\end{aligned}
$$

\section{Variables/Arrays}

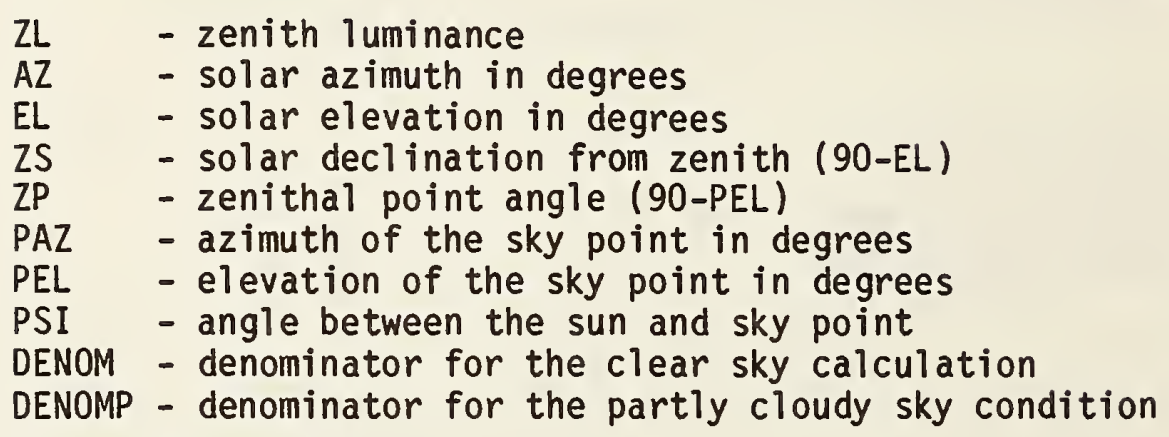

\subsection{SOLPOS}

\section{Purpose}

SOLPOS computes the elevation and azimuth of the sun as a function of the day of the year and the position on earth.

\section{Method}

1) Solar elevation is calculated by:

$$
a_{t}=\arcsin (\sin \ell \sin \delta-\cos \ell \cos \delta \cos (\pi t / 12))
$$

where $a_{t}=$ solar elevation

$\ell=$ site latitude

$\delta=$ solar declination

$t=$ solar time $[7]$.

2) Solar declination is calculated by:

$$
\delta=0.4093 \sin \left(\frac{2 \pi}{368}(\mathrm{~J}-81)\right)
$$

where $\delta=$ solar declination in radians

$\mathrm{J}=$ julian date $1 \leqslant \mathrm{~J}<365$ [7].

3) Solar azimuth is calculated by:

$$
\begin{aligned}
& \text { Positive - Afternoon } \\
& \text { Negative - Morning } \\
& a_{s}=\arctan \frac{\cos \delta \sin (\pi t / 12)}{\cos \ell \sin \delta+\sin \ell \cos \delta \cos (\pi t / 12)}
\end{aligned}
$$




$$
\text { where } \begin{aligned}
\mathrm{a}_{\mathrm{s}} & =\text { solar azimuth } \\
\ell & =\text { site latitude } \\
\delta & =\text { solar declination } \\
t & =\text { solar time }[7] .
\end{aligned}
$$

\section{Variables/Arrays}

LAT - latitude in degrees

L $\quad$ - latitude in radians

TIM - solar time

SUNAZ - solar azimuth

RADTODG - conversion from radians to degrees

DGTORAD - conversion from degrees to radians

DAY - julian date

DEL - solar declination

\subsection{VSKY}

\section{Purpose}

VSKY no longer computes a multiplier. It interpolates between vertical halfsky illuminance constants depending on the altitude and azimuth.

Method

1) The illuminance constants are contained in data statements. There are 19 statements for clear sky and 19 for partly cloudy.

2) The interpolation is the hyperbolic interpolation which is explained in section 2.2 of the CEL-1 Programmer's Guide [2].

3) For overcast sky condition, the method is the same as the original [2]. Variables/Arrays
D11 - hyperbolic interpolation coefficient
D12 - hyperbolic interpolation coefficient
D21 - hyperbolic interpolation coefficient
D22 - hyperbolic interpolation coefficient
P1 thru P19 - arrays containing 19 elements of vertical half-sky $i l l u m i n a n c e$ constants for partly cloudy sky condition
C1 thru C19 - arrays containing 19 elements of vertical half-sky 117 uminance constants for clear sky condition
$\mathrm{CL} \quad-19 \times 19$ array containing C1-C19
PC $\quad-19 \times 19$ array containing P1-P19 
3. CEL-1.1 TAPES

All of the CEL-1.1 program files are stored on tape at Boeing Computer Services. There are two tapes available to the user.

Tape \#1: This tape contains all the CEL-1.1 program files. These include:

- FORTRAN Source Files

- FORTRAN Binary Files

- Data Files

- Procedure files

- Program Support Files

Tape \#2: This tape contains only the files necessary for running CEL-1.1. These include:

- FORTRAN Binary files

- Data Files

- Procedure Files

Refer to section 4 for further information about accessing these tapes. 


\section{INTERACTIVE CAPABILITIES}

\subsection{CELJOBS}

CELJOBS is a procedure file which calls JOBS, an interactive program. JOBS asks questions and the user supplies the necessary information. The user is asked questions about what type of program to run, which program to run, account infomation, job priority, and submitting the job.

JOBS allows the user to access 4 batch programs and 2 interactive programs. (Only one program can be chosen with each run of CELJOBS.) The four batch programs are:

- GATHRUN will submit the job to access tape \#2 (run files only).

- GATHALL will submit the job to access tape \#1 (all files).

- RUNOUT will remove the files on tape \#2 from the user's account. This should be done after the user has finished running CEL-1.1 due to the fact that it is rather expensive to keep the files on the account for long periods of time.

- ALLOUT will remove all the files on Tape \#1 from the user's account. The suggestion for RUNOUT should be followed for ALLOUT, also.

The 2 interactive programs are CELIII and CEL1FE. Both of these programs are explained in the original CEL-1 User's Manual [3].

Refer to appendix $\mathrm{C}$ for information on accessing CELJOBS.

\subsection{CELIPP}

The preprocessor has been modified to generate the data deck for the BLAST Lighting Schedule run. The program requests the julian date of the first Saturday of the year, the julian date of the first and last days of the requested schedule for the run, and in the calculate block, the key "BLS" can be used to request the BLAST run.

At the end, the preprocessor will check for the necessary weather data on the user's account. If it is not available, a message will be printed.

Note: The user should not enter a blank line when running the preprocessor. This will end the preprocessor session.

\subsection{CEL1II}

CEL1II has been modified so that it no longer uses Tape2 = Sites. This is due to a change in ZIFACE. ZIFACE does not ask for the user's location code. Instead, the user is asked if there is a file called MAILBOX on the user's account. This file contains the mailing information of the user. 
ZIFACE has been modified to ask about the type of account the user has at BCS. If it is a QUE-PASA account, the user is asked for charge information.

The other modifications to ZIFACE are in the code for constructing the job file depending on the disposition of the output. For a further explanation of the "ROUTE" command and the parameters associated with it, refer to the EKS Control Statement Manual [4].

\subsection{CREATING THE CEL-1.1 DATA DECK USING CELUOBS AND CELIFE \\ C>GET,CELJOBS \\ C>CELJOBS}

-DO YOU HAVE THE NECESSARY FILES ON YOUR ACCOUNT TO RUN THE PROGRAM OF YOUR CHOICE? $(Y / N)$

$\mathrm{I}>Y$

-DO YOU WANT TO RUN A BATCH JOB?(Y/N)

$\mathrm{I}>\mathrm{N}$

-DO YOU WANT TO RUN AN INTERACTIVE PROGRAM?(Y/N)

$I>Y$

-ENTER ID OF PROGRAM YOU WANT TO RUN:

$$
\begin{aligned}
5 & =\text { CELIII } \\
6 & =\text { CELIFE } \\
1>6 &
\end{aligned}
$$

-ENTER 5 LINES OF LABEL INFORMATION, MAX 80 CHARS PER LINE:

1>CEL -1.1: EXAMPLE DATA DECK IN PROFILE MODE

1 $>$ WEATHER DATA INPUT

1 $>$ HOURLY BLAST LIGHTING SCHEDULES OUTPUT

1>JULIAN DATES PROCESSED: 106 THRU 110

1

-ENTER INPUT UNITS, OUTPUT UNITS ( $1=$ ENGLISH 2=METRIC). ENTER 2 VALUES:

$1>12$

-ENTER ROOM DIMENSIONS, DISCRETIZATION $\neq 5$ IN PARIS:

$-W I D T H(E-W)$

$1>5.25$

-LENGTH $(\mathrm{N}-5)$

$1>11.211$

- HE IGHT

$1>6.96$

-ENTER SURFACE REFLECTANCES IN THIS ORDER:

WEST WALL, NORTH WALL, EAST WALL, SOUTH WALL, FLOOR CEILING 
$1>.47 \quad .47 \quad .47 \quad .47 \quad .30 \quad .85$

-HOW MANY ROOM SURFACE INSERTS

$1>0$

-DO YOU WANT TO USE DAYLIGHT (Y/N)

$12 Y$

-HOW MANY OBSTRUCTIONS ARE PRESENT IN THE ROOM

$1>0$

-DO YOU WANT TO COMPUTE ESI RATINGS ( $Y / N$ )

$1>N$

-ARE TASK LOCATIONS ON A RECTANGULAR GRID ( $Y / N)$

$1>Y$

-ENTER DETAILS FOR GRID OF TASK LOCATIONS:

- $\neq$ COLUMNS (MAX 10)

$1>2$

$-\neq$ ROWS (MAX 10)

$1>2$

-LEFTMOST X-COORDINATE

$1>2$

-RIGHTMOST X-COORDINATE

$1>4$

-LOWEST Y-COORDINATE

$1>3$

-HIGHEST Y-COORDINATE

$1>6$

-HEIGHT ABOVE FLOOR

$1>2.5$

-OBSERVER EYE HEIGHT

$1>4$

-HOW MANY VIEWING DIRECTIONS

$1>1$

-ENTER 1 VIEWING DIRECTION ANGLES

$1>0$

-ENTER $\neq$ INTERIOR SENSORS, $\neq$ EXTERIOR SENSORS

$1>30$

-FOR EACH INTERIOR SENSOR, ENTER 4 PARAMETERS:

$X$-COORD, Y-COORD, Z-COORD, ORIENTATION (5 or 6)

LOC $\neq 1:$

$1>266 \quad 2.8 .2 .56$

LOC $\neq 2:$

$1>2.65 .52 .56$

LOC $\neq 3$ :

$1>2.67 .42 .56$ 
-HOW MANY WINDOW TYPE DEFINITIONS (Max 10)

$1>1$

-.---FOR WINDOW DEFINITION $\neq 1$-....-

$1>1$

GLAZING ( $1=$ CLEAR, 2=DIFFUSING)

'TRANSMITTANCE

$1>.67$

WIDTH, HEIGHT OF WINDOW

$1>5.22 .8$

$1>1$

HOW MANY LOCATIONS (MAX 50)

FOR EACH LOCATION, ENTER THESE 4 PARAMETERS

SURFACE $\neq,(X, Y, Z)$ COORDINATES OF CORNER NEAREST ORIGIN

LOC $\neq 1:$

$\begin{array}{llllllllll}1>2 & 0 & 11.2 & 3.1\end{array}$

ARE THERE PULL-DOWN SHADES ON THESE WINDOWS ( $Y / N$ )

$I>N$

ARE THERE DRAPES ON THESE WINDOWS ( $Y / N)$

$1>N$

ARE THERE BLINDS ON THESE WINDOWS ( $Y / N$ )

$I>N$

DO THESE WINDOWS HAVE A LIGHT SHELF ( $Y / N)$

$1>N$

ARE THERE BARRIERS OUTSIDE THESE WINDOWS $(Y / N)$

$1>N$

-HOW MANY CLERESTORY TYPE DEFINITIONS (MAX 9)

$1>0$

- HOW MANY SAWTOOTH TYPE DEFINITIONS (MAX 9)

$1>0$

-HOW MANY SKYLIGHT TYPE DEFINITIONS (MAX 9)

$1>0$

-HOW MANY BUILDINGS

$1>1$

-------FOR BUILDING $\neq 1$----.--

$(X, Y, Z)$ COORDINATES OF LOWER SOUTHWEST CORNER $1>-1-1 \quad-1$ 
E-W DIMENSION, N-5 DIMENSION, HEIGHT

$1>7.213 .28 .9$

REFLECTANCES, IN THIS ORDER: WEST FACE, NORTH FACE,

EAST FACE, SOUTH FACE, ROOF

$1>.6 .6 .6 .6 .2$

BUILDING ANGULAR DISPLACEMENT FROM TRUE NORTH

$1>0$

-WHAT IS GROUND REFLECTANCE

$1>.2$

-HOW MANY GROUND INSERTS

$1>0$

-ENTER LATITUDE OF SITE, LONGITUEd OF SITE, LONGITUDE AT CENTER OF TIME ZONE, WEATHER STATION ID

$1>38.577 .075 .053$

ENTER DAYLIGNT SAVINGS TIME MAP (12 BINARY VALUES)

$1>0000001111111100$

- IS THIS AN ENERGY PROFILE RUN ( $Y / N$ )

$1>Y$

ENTER 24 OCCUPANCY FACTORS (ONE FOR EACH 24-HOUR PERIOD), BEGINNING WITH THE PERIOD (12 MIDNIGHT - 1 A. M.):

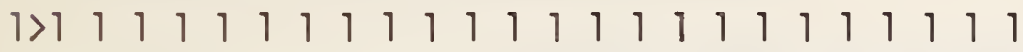

-ENTER THE JULIAN DATE OF THE FIRST SATURDAY OF THE YEAR OF THE BLAST

SCHEDULE (OR 1 IF BLAST SCHEDULE WILL NOT BE REQUESTED)

$1>1$

- ENTER THE FIRST AND LAST DAYS DESIRED FOR THE BLAST LIGHTING SCHEDULE. THE PERIOD SHOULD BE NO MORE

THAN 183 DAYS TOTAL. THE DAY SHOULD BE IN THE FORM OF A THREE DIGIT NUMBER, JULIAN DATE.

IF BLAST SCHEDULE WILL NOT BE REQUESTED ENTER 1 FOR BOTH

$1>106110$

-WHICH METRICS DO YOU WANT TO PRINT OUT:

DO YOU WISH TO RUN THE BLAST LIGHTING SCHEDULE

GENERATION PROGRAM ( $Y / N)$

$\star * \star$ THIS OPTION WILL PREVENT ANY OTHER OPTIONS

$\star \star \star$ FROM EXECUTING

$1>Y$

-WHAT IS NAME OF FILE WITH BKGD LUMINANCE BROF FACTORS $1>P 25 B$

-WHAT IS NAME OF FILE WITH TASK LUMINANCE BRDF FACTORS

$1>P 25 T$

-HOW MANY DIFFERENT TYPES OF LUMINARIES DO YOU INTEND TO USE $1>1$ 
-FOR LUMINAIRE TYPE $\neq 1$ :

-WHAT IS PHOTOMETRIC FILE NAME

$1>\mathrm{HB} 43$

-TOTAL INITIAL LAMP LUMENS PER LUMINAIRE

$1>1250$

-LIGHT LOSS FACTOR

$1>1$

-WIDTH OF LUMINOUS OPENING

$1>2$

-LENGTH OF LUMINOUS OPENING

$1>4$

-HEIGHT OF LUMINAIRE

$1>0$

- HOW MANY WATTS CONSUMED BY EACH LUMINAIRE

$1>150$

-WHAT IS MINIMUM GAIN (=FRACTION OF LIGHT OUTPUT) TO WHICH

LUMINAIRE CAN BE DIMMED OR SWITCHED ( $0=$ OFF, $1.0=100$ LIGHT OUTPUT)

$1>0$

-ENTER 3 QUADRATIC COEFFICIENTS A,B,C SUCH THAT

WATTS = A X GAIN X GAIN + BX GAIN + C

$1>01500$

-HOW MANY LUMINAIRES THIS TYPE

$1>2$

-FOR EACH LUMINAIRE ENTER $X, Y, Z$ COORDINATES AFTER ' $(X, Y, Z)$ ' PROMPT ENTER BEARING, TILT, CANT AFTER 'ORIENT' PROMPT.

$-\operatorname{LUM} \neq \quad 1:$

$(X, Y, Z)$

$1>2.62 .86 .9$

OR IENT

$1>0 \quad 00$

- LUM $\neq \quad 2:$

$(X, Y, Z)$

$1>2.69 .06 .9$

ORIENT

$1>000$

-FOR DIMMING/CONTROL OF LUMINAIRES, ENTER CONTROL MEHTHOD:

$1=$ ON-OFF (GROUP CONTROL)

$-1=$ ON-OFF (INDIVIDUAL CONTROL)

$2=$ HIGH-LOW-OFF (GROUP CONTROL)

$-2=$ HIGH-LOW-OFF (INDIVIDUAL CONTROL)

3 = CONTINUOUS DIMMING (GROUP CONTROL)

-3 = CONTINUOUS DIMMING (INDIVIDUAL CONTROL)

$1>-3$

-ENTER 1 CONTROL CRITERION VALUE(S)

$1>50$ 
-SELECT THE CONTROLLING ILLUMINANCE VALUE FROM THESE:

1 - MINIMUM ILLUMINANCE OVER TARGET POINTS

2 - AVERAGE ILLUMINANCE OVER TARGET POINTS

3 - MINIMUM ILLUMINANCE OVER CONTROL TARGET AREA

4 - AVERAGE ILLIMINANCE OVER CONTROL TARGET AREA

5 - MINIMUM ESI OVER THE TARGET POINTS

$1>1$

- HOW MANY LUMINAIRES ALWAYS OFF:

$1>0$

-HOW MANY LUMINAIRES TO BE DIMMED/CONTROLLED

$1>2$

ENTER SEQUENCE $\neq 5$ of 2 LUMINAIRES TO BE DIMMED/CONTROLLED

$1>12$

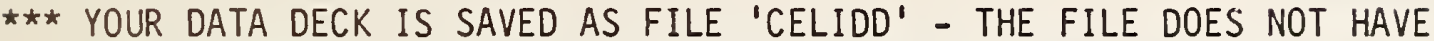
LINE NUMBERS. YOU MAY LIST THE FILE AND/OR CHANGE IT USING THE NOS

EDITOR. TO SUBMIT THE DECK FOR EXECUTION, KEY IN:

GET,CELIII

-CELI I I

4.5 CREATING A BATCH JOB USING CELJOBS

C>-CELJOBS

-DO YOU HAVE THE NECESSARY FILES ON YOUR ACCOUNT

TO RUN THE PROGRAM OF YOUR CHOICE? $(Y / N)$

-DO YOU WANT TO RUN A BATCH JOB?(Y/N) $1>Y$

-ENTER ID OF PROGRAM YOU WANT TO RUN:

1 = GATHRUN

2 = GATHALL

$3=$ RUNOUT

$4=$ ALLOUT

$1>2$

-ENTER THE PRIORITY YOU WANT TO RUN AT: (12 FORMAT) $(1,2,4,6,10,11,13$ )

(PRIORITY IS LISTED LOWEST TO HIGHEST) $1>01$ $1>Y$

-DO YOU WANT TO SUBMIT THIS JOB?(Y/N)

-IS YOUR ACCOUNT A QUC-PASA ACCOUNT?(Y/N) $1>Y$ 
-ENTER YOUR CWA ACCOUNT NAME--(6 LETTER NAME) $1>M Y C W A N$

-ENTER YOUR PROJECT NUMBER--(4 DIGIT NUMBER)

$1>1111$

$0857 \quad 48 \quad 83 / 11 / 29 . T 10 I B D T$

C)GETFILE, TIOTBDT

TIOIBDT IS NOW LOCAL FILE TIOIBDT

C>CME, TIOIBOT

$E>P \star$

TAPE 1,P01

USER , *

CHARGE, MYCWAN, 111

GET, GATHALL /UN $=$ NB5007

GATHALL

EDI

4.6 SUBMITTING THE CEL-1.1 DATA DECK USING CELJOBS AND CELIII

C>-CELJOBS

-DO YOU HAVE THE NECESSARY FILES ON YOUR ACCOUNT

$1>Y$

TO RUN THE PROGRAM OF YOUR CHOICE?(Y/N)

$1>N$

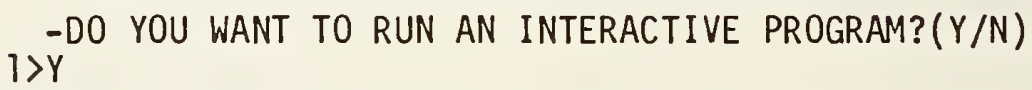

-DO YOU WANT TO RUN A BATCH JOB?(Y/N)

-ENTER ID OF PROGRAM YOU WANT TO RUN:

$5=$ CELIII

$6=$ CELIFE

$1>5$

-- CEL-1 INTERACTIVE INTERFACE --

- ENTER ID OF PROGRAM YOU WANT TO RUN

$$
\begin{aligned}
& 1=\text { CEL- } 1 \\
& 2=\text { OBMP } \\
& 3=\text { CCMP }
\end{aligned}
$$

$1>1$ $1>01$

-ENTER PRIORITY FOR JOB $(1,2,4,6,10,11,13)$ (12 FORMAT)

-ENTER CODE FOR DISPOSITION OF OUTPUT:

1 ROUTE TO YOUR REMOTE BATCH TERMINAL

2 PRINT AT CENTRAL SITE, MAIL TO YOU

3 SAVE FOR SUBSEQUENT RETRIEVAL AT INTERACTIVE TERMINAL 
$1>3$

-DO YOU WANT TO SUBMIT THIS JOB? (Y/N) $1>Y$

-IS YOUR ACCOUNT A QUE-PASA ACCOUNT?(Y/N) $1>Y$

-ENTER YOUR CWA ACCOUNT NAME--( 6 LETTER NAME) I $>M Y C W A N$

-ENTER YOUR PROJECT NUMBER--(4 DIGIT NUMBER) $1>1111$

$085232 \quad 83 / 12 / 12 . T 101 E P T$ EXIT 


\title{
5. COMPILING THE ROUTINES
}

\subsection{FT PROCEDURE}

FT is used to compile the main program source files. To use the procedure type in:

\author{
- GET, FT \\ FT,Zfilename, filename
}

where $Z$ filename = main program source file filename = main program name.

For a list of main program source files, refer to the CEL-1 Programmer's Guide [2].

Note: C3435B must be compiled with FT. To compile, type in:

FT, C3435B, C3435.

\subsection{LIBREPL PROCEDURE}

LIBREPL is used to compile subroutine source files and replace the old compiled version in NBSOPT2 with the new compiled version.

A subroutine source file contains only subroutines and functions. Refer to the CEL-1 Programmer's Guide for a list of subroutine source files [2]. The new subroutine files are: INIT, WEATHER, LOOP, CEL34B, CEL35B, DAYEFB, ZENLUMB, MONDAY, BLSTOUT.

To use LIBREPL type in:

GET,LIBREPL

LIBREPL, fi lename

where filename $=$ program name. If there are errors check the listing file, $L$, using CMEDIT.

Note: To use LIBREPL, the filename must be the same as the program or subroutine name. The subroutine source files, listed in the CEL-1 Programmer's Guide, have no " $Z$ " as the first letter of the file names [2].

\subsection{LIBIT PROCEDURE}

LIBIT creates the relocatable library, RELOC, from the file NBSOPT2. This routine must be used after using LIBREPL. If it is not, the new compiled versions will not be in RELOC. 
To use LIBIT type in:

GET, LIBIT

LIBIT

Note: Both NBSOPT2 and RELOC are direct access files. The "ATTACH" command must be used to access them.

\subsection{LIBINS PROCEDURE}

LIBINS inserts a new compiled file into the relocatable library. To use LIBINS the filename must be the same as the program name.

Type in:

GET, LIBINS

LIBINS, filename, extfile

where filename $=$ program name

extfile $=$ file which the inserted file should be place before in RELOC 
6. SUMMARY

This report contains:

a) a description of the modified capabilities of the Daylight subset of CEL-1.1

b) a description of the BLAST generator and the output of hour-by-hour lighting power multipliers

c) an explanation of the interactive capabilities of CEL-1.1

d) an explanation of the use of the BOEING COMPUTER SYSTEM

e) new updates to the existing CEL-1 manuals 


\section{REFERENCES}

1. Treado, S. and Kusuda, T., Solar Radiation and Illumination, NBS Technical Note 1148, November 1981.

2. CEL-1 Lighting Computer Program - Programmer's Guide, CR 83.009, Naval Civil Engineering Laboratory, Port Hueneme, CA, 93043, January 1983.

3. CEL-1 Lighting Computer Program - User's Guide, CR 81.026, Naval Civil Engineering Laboratory, Port Hueneme, CA, 93043, September 1981.

4. MAINSTREAM - EKS Control Statement Manuai, 10208-133, Boeing Computer Services Company, March 1981.

5. MAINSTREAM - EKS Users Guide, 10208-132, Boeing Computer Services Company, October T98T.

6. MAINSTREAM - EKS Interactive Timesharing (KIT) Users Manual, 10208-005, Boeing Computer Services Company, October 1977.

7. Recommended Practice for the Calculation of Daylight Availability, IES Journal, Vol. 13, No. 4, July, 984. 


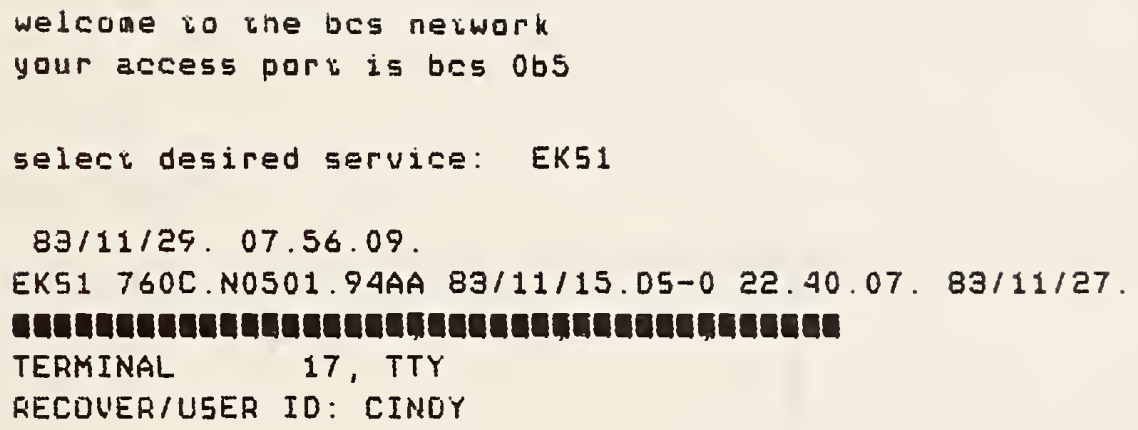

Figure 2. An example of the signon procedure 


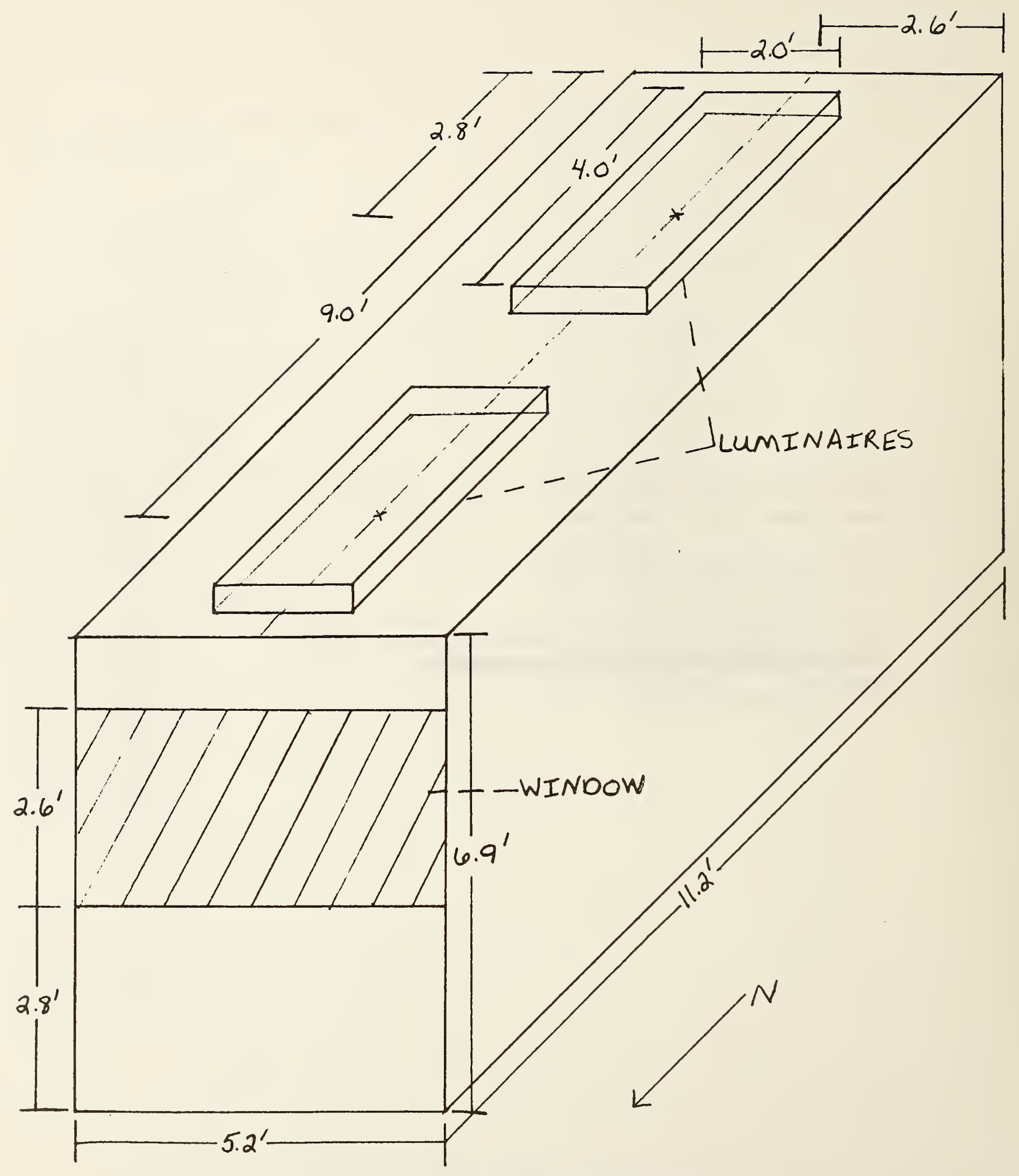

Figure 3. Room Layout for CEL-1.1 example data deck 
APPENDIX A. COMPUTER TERMINOLOGY AND SYMBOLS FOR BOEING COMPUTER SYSTEM The user should understand the following terms and symbols related to the computer before signing on:

User number - a seven character number used to signon at the start of a KIT session

QUE-PASA - an optional EKS interactive accounting system [5]

Charge number - a ten character number assigned by BCS for QUE-PASA accounts

CWA - Computer Work Authorization account name ( 6 characters)

Project number - an internal accounting identifier for a charge number (4 digit number)

CMEDIT - timesharing text editor [6]

EKS1 - provides batch and interactive services using control data Cyber mainframes

CR - carriage return

P \# - CMEDIT command which prints the requested number of lines of text 
APPENDIX B. SIGNON PROCEDURE

Before signing on, have the assigned account number, password, QUE-PASA project number, and the local Boeing Computer Services phone number. The phone number used depends on the desired line speed and the location. Set the terminal according to the MAINSTREAM-EKS KIT manual [6].

Dial up the EKS Data Center. Once connected, the following interaction takes place: (the responses entered by the user are underlined).

welcome to the bsc network

your access part is bsc Obd

select desired service: EKS1 CR

YY/MM/DD.HH.MM.SS.

EKS1 760A.N0501.64C YY/MM/DD.DS-O HH.MM.SS.YY/MM/DD

USER NUMBER: MYUSER CR

PASSWORD: $\underline{\text { MYPASSW }}$ CR

CHARGE: MYCWA, MYPROJ CR

TERMINAL: $n n n$, i i i

RECOVER/USERID: NAME CR

where nnn is the terminal number assigned by KIT

iij is the identifier which describes the type of terminal [6]

C)

At this point, the signon is complete and EKS1 is ready to accept commands. Figure 2 shows an example of the signon procedure.

Note: (1) The user number, password, and charge are blacked out after entering the carriage return.

(2) If the account is not a QUE-PASA project, then the request for a CHARGE will not appear.

(3) If the terminal disconnects, recovery can be accomplished by typing:

EKSP when the system prompts with "select desired service." If the system responds with "RECOVERY IMPOSSIBLE," signoff with the command BYE. Then enter EKSS. 
APPENDIX C. ACCESSING CELJOBS AND RELATED COMPUTER COMMANDS

To access CELJOBS, type:

GET, CELJOBS

-CELJOBS

This will start the interactive session. Once CELJOBS has started, the user is asked if the necessary files are available on the user's account. (Refer to appendix $D$ for a list of files.) If the user does not have the appropriate files, CELJOBS gives a message and terminates.

When the job has been submitted, the user will get the following message:

HH.MM.SS. YY/MM/DD .JOBNAME.

The jobname consists of the "index hash" which is the first four characters of the jobname. (These four characters will always be the same.) The last 3 characters are generated randomly.

To check on the status of the job, type:

FIND, JOBNAME, $L O=F$.

The user is given information about the job such as: jobname, mainframe job is on, processing queue, elapsed time, when the job is executing and finished.

When the job has finished, the user should get the file. This is done by:

GETFILE, JOBNAME

The computer responds with:

FILE JOBNAME is now local file JOBNAME.

This file can then be checked for any errors that might have occurred during the job run by using CMEDIT.

If the user chooses to run CELIII, the output will be in a direct access file.

To access a direct access file, type:

ATTACH, filename

CME, filename

$P \#$ 
APPENDIX D. NECESSARY FILES FOR RUNNING CELJOBS

For each of the six programs, certain files are needed in order to run the programs. Each program is shown with a list of files that are needed on the user's account.

$\begin{array}{ll}\text { Program } & \text { Files } \\ \text { RUNOUT } & \begin{array}{l}\text { RUNOUT } \\ \text { Files from Tape \#2 } \\ \text { (run files) }\end{array} \\ \text { ALLOUT } & \begin{array}{l}\text { ALLOUT } \\ \text { Files from Tape \#1 } \\ \text { (all files) }\end{array} \\ & \text { CEL1II } \\ \text { CELIII } & \text { IFACE } \\ & \text { CHECK } \\ & \text { ERRORS } \\ & \text { RELOC } \\ & \text { (rUn files) } \\ \text { CEL1FE } & \text { CEL1FE } \\ & \text { CEL1PP } \\ & \text { RELOC }\end{array}$


APPENDIX E. COMMON BLOCK VARIABLE DEFINITIONS

\section{E.1 COMMON BLOCK /DATA/}

This common block is the "basic" block for the modified version in that it contains all the variables used by the modified programs and the new additional programs and subroutines.

AJDAY - a linear array of 15 julian dates ( 5 for each of 3 days)

AMONTH - a linear array containing the number of the month (15 elements)

ATTIME - a linear array of 15 hours

ADAY - a linear array containing the number of the day (values - 1 to 31 )

CMER - center meridian

DSTMAP - array of 12 zeros and ones representing the months of the year with daylight savings time

DY1 - julian date of the first Saturday in the year

FRSTDY - julian date of the first day of the run

LAT - latitude

LON - longitude

LSTDY - julian date of the last day of the run

E.2 COMMON BLOCK/WEATH/

This common block contains variables which describe the weather data (see section 3.3 for more details).

CR - array of 15 cloud ratios, one for each of five hours for three days

EDIF - arary of 15 elements containing diffuse illuminance, one for each of five hours for three days

EDIR - arrays of 15 elements containing direct $i 1$ luminance, one for each of five hours for three days 
APPENDIX F. LOGICAL UNIT ASSIGNMENTS

The list below shows the logical unit numbers of the disc files used in CEL-1.1, with the description and the variable name used to refer to the file.

\begin{tabular}{|c|c|c|}
\hline Number & Variable Name & Description \\
\hline 95 & LUBS & initial values for DY1, FRSTDY, LSTDY \\
\hline 96 & LUWEA & $\begin{array}{l}\text { processed weather data (cloud ratio, } \\
\text { illuminances) }\end{array}$ \\
\hline 97 & WTHRFL & $\begin{array}{l}\text { unprocessed BLAST weather data } \\
\text { (irradiances) }\end{array}$ \\
\hline 98 & LULPM & $\begin{array}{l}\text { lighting power multipliers (energy } \\
\text { profile consumption for each day } \\
\text { and hour) }\end{array}$ \\
\hline
\end{tabular}


APPENDIX G. PROGRAM CALLING SEQUENCE TREE

The diagram below defines the subroutine and function linkages of CEL-1.1. The notation is the same as in the CEL-1 Programmer's Guide [2].

C3435B

INIT

- WEATHER

SOLOPS

LOOP

MONDAY

SRSET

CEL34B

SOLPOS

DAYEFB

TRIGS

ZENLUMB

CEL35B

QLUM

CMPRES

MSTRSN

ACC1L

CONTR I

OSCU

SLOPE

CEVAL

DIGITIZ

BLSTOUT

MONDAY 
APPENDIX H. CEL-1.1 DATA DECK

\section{ROOM}

CEL-1.1: EXAMPLE DATA DECK IN PROFILE MODE

WEATHER DATA INPUT

HOURLY BLAST LIGHTING SCHEDULES OUTPUT

JULIAN DATES PROCESSED: 106 THRU 110

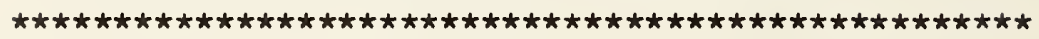

$$
12
$$

TASK

$$
\begin{array}{lllllll}
5.20 & 5 & 11.20 & 11 & 6.90 & 6 & \\
.470 & .470 & .470 & .470 & .300 & .850
\end{array}
$$

UNKNOWN

$$
\begin{array}{llllllll}
2 & 2 & 2.00 & 4.00 & 4.00 & 8.00 & 2.50 & 5.80 \\
& \begin{array}{lllll}
2.00 \\
\text { SENSORS }
\end{array} & 0.00 & & & & &
\end{array}
$$

3

$$
\begin{array}{llll}
2.60 & 2.80 & 2.50 & 6 \\
2.60 & 5.50 & 2.50 & \\
2.60 & 7.40 & 2.50 & 6
\end{array}
$$

0

FENESTRATION

WINDOW

$$
\begin{aligned}
& 1 \quad .670 \\
& 5.20 \quad 2.80 \\
& 2 \quad 0.00 \quad 11.20 \quad 3.10
\end{aligned}
$$

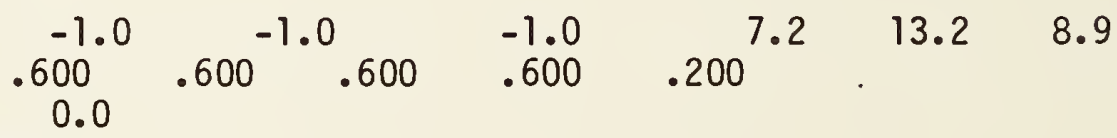

$$
.200
$$

PROFILE

$$
\begin{array}{lllllll}
38.50 & 77.00 & 75.0 & 53 & 1 & 106 & 110
\end{array}
$$

$$
0000111111000
$$

1. 1.1.1.1.1.1.1.1.1.1.1.1.1.1.1.1.1.1.1.1.1.1.1. LUMINAIRES HB43

$$
\begin{array}{ccccccc}
1250.0 & 1.000 & & & & \\
2.000 & 4.000 & 0.000 & 150.0 & & \\
0.000 & 0.00 & 150.00 & 0.00 & & \\
2 & & & & & & \\
1 & 2.60 & 2.80 & 6.90 & 0.0 & 0.0 & 0.0 \\
2 & 2.60 & 9.00 & 6.90 & 0.0 & 0.0 & 0.0
\end{array}
$$




$$
\begin{aligned}
& \text { Dimming } \\
& -3 \\
& 50.0 \\
& 10000 \\
& \begin{array}{llllll}
0 & 0 & 0 & 0 & 0 & 0
\end{array} \\
& 0 \\
& \text { i } \\
& \text { - } 12 \\
& \text { HOR BLS } \\
& \text { P25B }
\end{aligned}
$$




\section{APPENDIX I. BLAST SCHEDULE OUTPUT EXAMPLE}

THESE FILES MUST BE INSERTED INTO AN EXISTING BLAST DECK. THE SCHEDULE AND LIGHTS STATEMENT FILES ARE SEPARATED BY THE CHARACTERS ' $\$ \$ \$$ '. $\$ \$ \$ \$$

DEFINE SCHEDULE (WEEK 1):

SUNDAY $=(0.00,0.00,0.00,0.00,0.00,0.00,0.00,0.00,0.00,0.00,0.00$, $0.00,0.00,0.00,0.00,0.00,0.00,0.00,0.0,0.00,0.00,0.00,0.00,0.00)$,

MONDAY $=(1.00,1.00,1.00,1.00,1.00,1.00,1.00,1.00,1.00,1.00, \quad .74$ $.18, .05, .59,1.00, .72, .18,1.00,1.00,1.00,1.00,1.00,1.00,1.00)$

TUESDAY $=(1.00,1.00,1.00,1.00,1.00,1.00,1.00,1.00,1.00,1.00,1.00 .76$ $.25,0.00,0.00,0.00, .03, .08,1.00,1.00,1.00,1.00,1.00,1.00,1.00)$, WEDNESDAY $=(1.00,1.00,1.00,1.00,1.00,1.00,1.00,1.00,1.00,1.00,1.00$ $1.00,1.00,1.00,1.00,1.00,1.00,1.00,1.00,1.00,1.00,1.00,1.00,1.00)$, THURSDAY $=(1.00,1.00,1.00,1.00,1.00,1.00,1.00,1.00, .58, .19, .01$ $0.00,0,00,0.00,0.00, .35, .83,1.00,1,00,1.00,1.00,1.00,1.00,1.00)$,

FRIDAY $=(1.00,1.00,1.00,1.00,1.00,1.00,1.00,1.00, .58, .19, .01$ $0.00,0.00,0.00,0.00, .35, .83,1.00,1.00,1.00,1.00,1.00,1.00,1.00)$, SATURDAY $=(0.00,0.00,0.00,0.00,0.00,0.00,0.00,0.00,0.00,0.00,0.00$, $0.00,0.00,0.00,0.00,0.00,0.00,0.00,0.00,0.00,0.00,0.00,0.00,0.00)$, HOLIDAY = SUNDAY END

DEFINE SCHEDULE (WEEK 2)

SUNDAY $=(0.00,0.00,0.00,0.00,0.00,0.00,0.00,0.00,0.00,0.00,0.00$, $0.00,0.00,0.00,0.00,0.00,0.00,0.00,0.0,0.00,0.00,0.00,0.00,0.00)$,

MONDAY $=1.00,1.00,1.00,1.00,1.00,1.00,1.00,1.00, .79, .57, .35$ $.11,0.00,0.00,0.00, .35 .83,1.00,1.00,1.00,1.00,1.00,1.00,1.00)$,

TUESDAY $=(1.00,1.00,1.00,1.00,1.00,1.00,1.00,1.00, .68, .38, .15$ $0.00, .08, .56, .99,1.00,1.00,1.00,1.00,1.00,1.00,1.00,1.00,1.00$ ),

WENSDAY $=(1.00,1.00,1.00,1.00,1.00,1.00,1.00,1.00,1.00,1.00,1.00$, $1.00, .92, .49, .11,0.00, .01,1.00,1.00,1.00,1.00,1.00,1.00,1.00)$,

THURSDAY $=(0.00,0.00,0.00,0.00,0.00,0.00,0.00,0.00,0.00,0.00,0.00$ $0.00,0.00,0.00,0.00,0.00,0.00,0.00,0.00,0.00,0.00,0.00,0.00,0.00$,

FRIDAY $=(0.00,0.00,0.00,0.00,0.00,0.00,0.00,0.00,0.00,0.00,0.00$ $0.00,0.00,0.00,0.00,0.00,0.00,0.00,0.00,0.00,0.00,0.00,0.00,0.00$,

Saturday $=(0.00,0.00,0.00,0.00,0.00,0.00,0.00,0.00,0.00,0.00,0.00$ HOLIDAY = SUNDAY $0.00,0.00,0.00,0.00,0.00,0.00,0.00,0.00,0.00,0.00,0.00,0.00,0.00$, END

$\$ \$ \$ \$$

LIGHTS = LIGHTS = $\$ \$ \$$

.30, WEEK 1 FROM 10 APR THRU 16 APR .30, WEEK 2 FROM 17 APR THRU 23 APR 
APPENDIX J. REVISIONS FOR THE CEL-1 USER'S GUIDE AND PROGRAMMER'S GUIDE

The following pages contain revisions and updates to reference 3. 
rev. $9-19-83$

$-17-$

Discussed fully in Section $V$.

6300. 82

This card gives, respectively, the total initial lamp lumens and the light

loss factors to be used. The initial lamp lumens value is the initial

lumen rating for one lamp multiplied by the number of 1 amps in the luminaire. The total lamp lumens for a particular fixture must be obtained from the manufacturer or the IES Handbook. The photometric files do not contain the actual total. The light loss factor (a real number in the range $0-1$ ) is a factor which accounts for lamp lumens depreciation, luminaire dirt accumulation, luminaire corrosion, ballast losses, etc.

\section{$\begin{array}{llll}1.833 & 3.833 & 0.5 \quad 92\end{array}$}

This card specifies the following:

1.833 - the width of the luminous opening of the luminaire.

3.833 - the length of the luminous opening of the luminaire.

Note that the length and width of the luminaire are independent of the luminaire's orientation in the room. To determine these values, imagine the luminaire positioned so that its 0 degree photometric plane is pointed north. Then the width of the E-W span of the luminous opening and the length is the N-S span of the luminous opening. For fluorescent luminaires, this 0 degree photometric plane is almost always parallel to the lamps. For HID luminaires (mercury vapor, metal halide, high-pressure sodium) with a horizontal $1 \mathrm{amp}$, the zero degree photometric plane is generally parallel to the arc tube of the 1 amp.

0.5 - the height of the luminaire. Unless a fixture has both uplight and downlight, this value may be specified as zero.

92 - says that the luminaire consumes 92 watts. This value only influences the calculations when an energy profile is being calculated, but it is recommended that the user cultivate the habit of always specifying it.

$\begin{array}{lllllll}0 & 0 & 0 & 0\end{array}$

This card contains 4 values which are used in energy profile calculations. The meaning of the values for energy profiles is discussed later in the section. If energy profile computations are not being performed, four zeros should be on the card.

6 - This card tells the program that we are going to locate six luminaires within the room. 


\subsection{Continuous Dimming}

We shall leave the room layout the same as in Example 10. The difference is that we want to control the luminaires in such a way that a threshold ESI value is maintained at each target point. Each luminaire can be dimmed independently; our goal is to minimize energy consumption while maintaining at least $30 \mathrm{ESI} \mathrm{fc}$ at each of the three task locations.

\section{ROOM}

EXAMPLE 11 -- ENERGY PROFILE WITH CONTINUOUS DIMMING CRITERION IS 30 ESI FC AT EACH TASK LOCATION

ALL SIX LUMINAIRES TO BE DIMMED.

SAME ROOM ENVIRONMENT AS FOR EXAMPLE 10.

11

$\begin{array}{llllll}40 & 20 & 30 & 15 & 10 & 5\end{array}$

$\begin{array}{llllll}.5 & .5 & .5 & .5 & .2 & .8\end{array}$

TASK

KNOWN

32.5

$13 \quad 8.5 \quad 0$

$\begin{array}{lll}30 & 8.5 & 0\end{array}$

$\begin{array}{lll}34.5 & 15 & -90\end{array}$

SENSORS

1

$\begin{array}{llll}20 & 15 & 10 & 5\end{array}$

$\begin{array}{llll}40 & 25 & 8 & 2\end{array}$

FENESTRATION

WINDOW

10.80

85

3

$\begin{array}{llll}4 & 16 & 0 & 3\end{array}$

$\begin{array}{llll}3 & 40 & 4 & 3\end{array}$

$\begin{array}{llll}3 & 40 & 17 & 3\end{array}$

BUILDING

2

$\begin{array}{llllll}-100 & 0 & -35 & 140 & 250 & 45\end{array}$

$\begin{array}{lllll}.6 & .6 & .6 & .6 & .2\end{array}$

$-30$

$\begin{array}{llllll}17 & -560 & -35 & 100 & 300 & 80\end{array}$

$\begin{array}{lllll}.5 & .5 & .5 & .5 & .5\end{array}$

$-15$

GROUND

.12

1

$\begin{array}{llllll}.08 & -150 & 250 & -200 & -50 & -35\end{array}$

FURNITURE

3

$\begin{array}{lllll}3 & 13 & 9.5 & 2.5 & 0\end{array}$ 


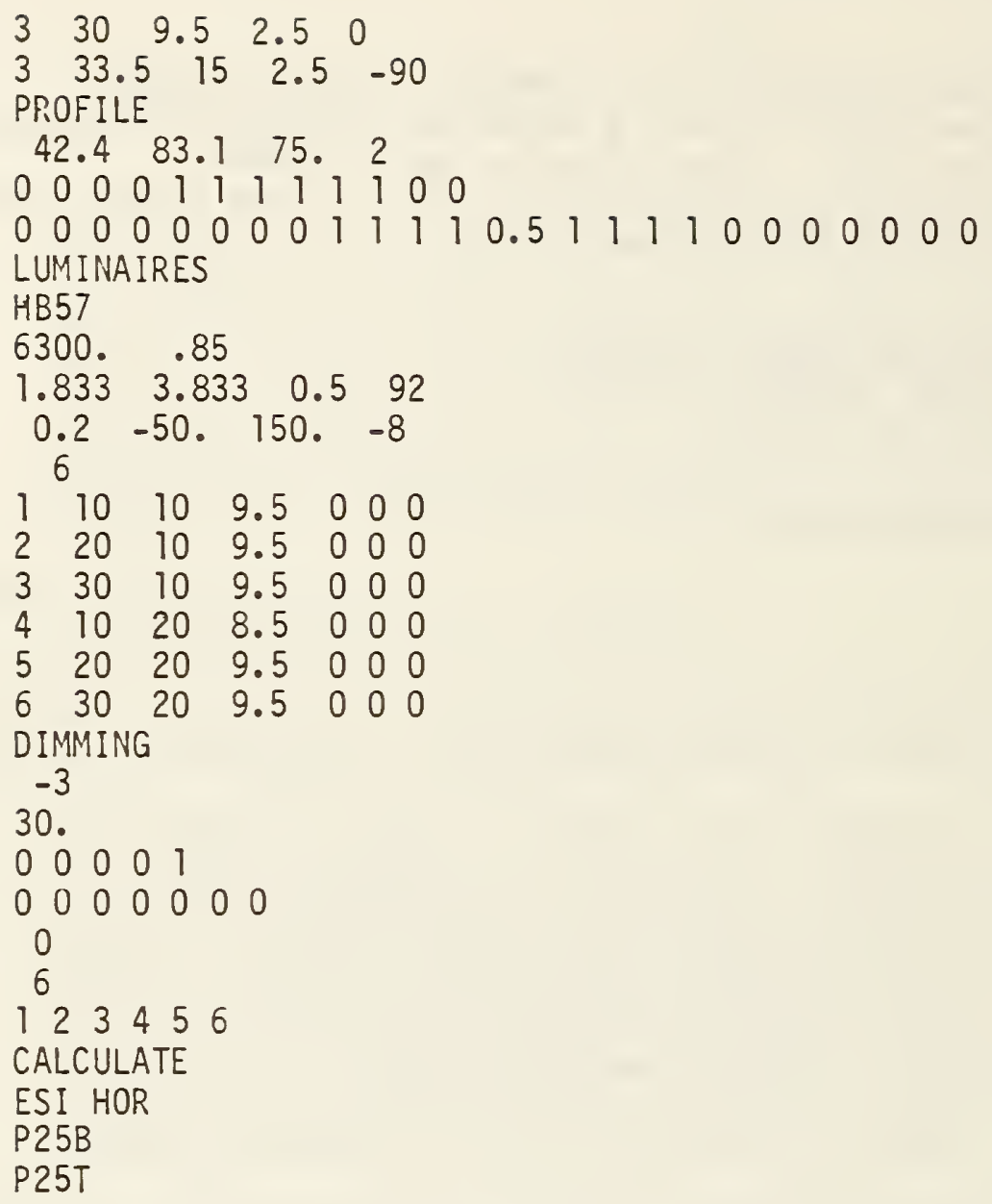

Note the following differences between this data deck and the deck for Example 10:

1. In the LUMINAIRES block the card

$$
0.2-50 \text {. 150. }-8
$$

has non-zero values on it for the first time in the examples we have considered. The 0.2 value is the minimum gain (=fraction of light output) to which the luminaire may be dimmed. In this case the luminaire cannot be dimmed below $20 \%$ light output. The remaining three numbers on the card consumption to gain as follows:

$$
\text { watts }=a \times \text { gain } 2+b \times \text { gain }+c
$$

In this case we have $a=-50, b=150, c=-8$. The watts computed from the above expression at full light output (gain $=1.0$ ) must always equal the watts given for the luminaire -- 92 in this case.

2. In the DIMMING block we have specified luminaire control method - 3 -- continuous dimming with each luminaire con- 
rev. $11-23-81$

\section{$-61-$}

trolled individually. We have also selected 30 ESI $\mathrm{fc}$ minimum as our criterion control value (this is done via the card 000001 ). Since the ESI criterion is applied to the target points themselves, we have no use for a control target area and therefore have not defined one (the card 00 00000 specifies 0 rows and 0 columns and therefore no control target area is defined). Also we have specified that all six luminaires are to be under diming control.

For energy profile calculations, any of the five controlling criteria may be specified, regardless of the luminaire control methol selected. The converse is not true, however, for when the criterion is minimum ESI, only continuous dimming may be specified.

It is important to note also that a positive luminaire control method $(1,2$, or 3 ) results in all controlled luminaires being dimmed together, while a negative luminaire control method $(-1,-2$, or -3$)$ results in each controlled luminaire being dimmed individually. 
$\begin{aligned} & * \text { - required input block } \\ & 0 \text { - optional input block } \\ & \text { (no entry) - block is forbidden }\end{aligned}$

The "capability set" refers to the CEL-1 capabilities being used, as follows:
A - no furniture, no daylight, unknown task $10 c^{\prime}$ ns
$B$ - furniture, no daylight, any tasks
C - design synthesizer
D - daylight, analysis mode
E - daylight, profile made
$F$ - daylight, BLAST generator
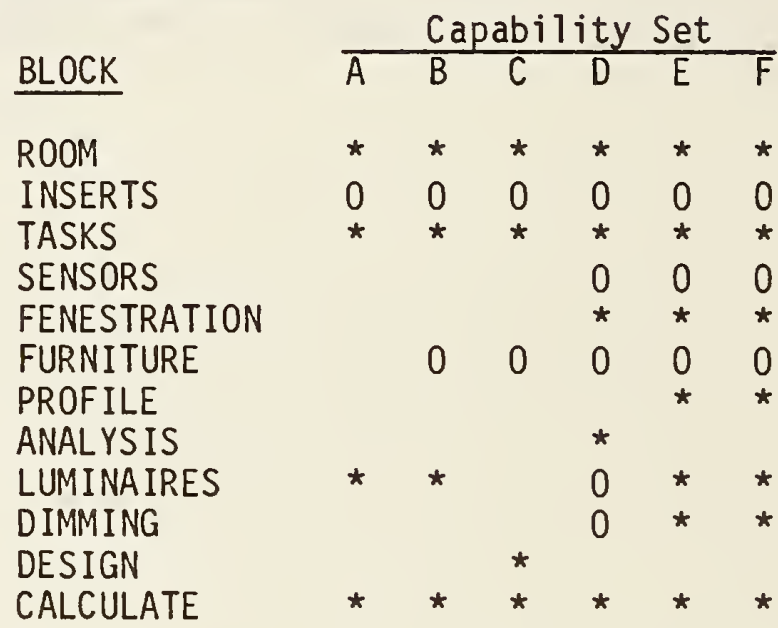

Data elements in the input stream will consist of three types:

a) alphabetic - these will be text ID lines, keywords, and file names. The latter two will have rigid column alignment requirements for their location on the line.

b) 'real' numeric - these may take on fractional values, if necessary. They may be entered with or without a decimal point. Their replacement on the input line is not subject to rigid column-alignment requirements, but each pair of numeric values must be separated by a comma and/or one or more spaces.

c) 'integer' numeric - these may not take on fractional values and must be coded in the input stream without a decimal point or numeric values must be separated by a comma and/or one or more spaces.

In the following discussions of the input blocks, numeric input variables are 'real' unless explicitly identified as 'integer'. 


\subsection{ROOM block}

The ROOM block must be presented in the input stream for all four CEL-1 programs. The ROOM block is as follows:

$\langle$ text ID line I〉

$\langle$ text ID line 2〉

$\langle$ text ID line 3〉

$\langle$ text ID line 4〉

$\langle$ text ID line 5〉

〈units definition>

$\langle$ room dimensions〉

〈room reflectances〉

These lines take the following forms:

〈text ID line $x$ 〉 - Each of these five lines may contain up to 80 characters of text which serves to identify the printed results. The contents of these lines are for identification purposes only in no way influence the computations.

〈units definition> - this line contains the two integer values:

〈input units〉 〈output units〉

where

〈input units〉 = 1 if all dimensions, distances, etc., are given in feet.

$=2$ if all dimensions, distances, etc., are given in meters.

〈output units> $=1$ if output values are to be in English units. In this case, computed luminance values will be given in footlamberts; computed illuminance values will be in footcandles.

2 if output values are to be in metric units. In this case, computed luminance values will be given in candelas per square meter; computed illuminance values will be in lux. 
rev. $11-23-81$

Consider the following Window sub-block examples:

Example 1:

$\begin{array}{llrl}\text { WINDOW } & \\ 1 & .9 & \\ 4 & 5 & & \\ & 3 & & \\ 1 & 0 & 8 & 2 \\ 1 & 0 & 18 & 2 \\ 1 & 0 & 28 & 2\end{array}$

BARRIERS

1. 1. $1.1 .1 .5 \quad .25$

$\begin{array}{llllll}-1 & 1 . & 1 . & 1.5 & .25\end{array}$

1. 1. $1.1 .1 .5 \quad .25$

$\begin{array}{lllll}0 & 0 & 0 & 0 & 0\end{array}$

SHELF

$$
\begin{array}{llllll}
0 \quad 1.0 & 0.75 & & & & \\
\text { BLINDS } & & & & \\
1.02083 & 0.1667 & 0.1458 & 30 & .80
\end{array}
$$

This example defines 3 windows on the west wall. Each window opening is $4^{\prime}$ across by $5^{\prime}$ high; the windows span $z$-coordinates $2-7$ and $y$-coordinates $8-12,18-22$, and 28-32. Barriers extend from each side and across the top of the exterior window opening. Each barrier has reflectance $=25 \%$ and protrudes 1.5 feet from the west wall. The side barriers are 1 ' on either side of the window opening and extend $l^{\prime}$ below the window opening. The top barrier is $l^{\prime}$ below the top window opening (this implies a sloping overhang which starts at the wall at or above the window opening). A light shelf protrudes $l^{\prime}$ ' into the room from the bottom of the window opening; its reflectance is $75 \%$. Venetian blinds are defined as follows:

$$
\begin{aligned}
& \text { thickness }-1 / 4 \text { inch }(=.02083 \text { foot }) \\
& \text { width }-2 \text { inches }(=.1667 \text { foot }) \\
& \text { spacing }-1.75 \text { inches }(=.1458 \text { foot }) \\
& \text { angle of opening }-30 \text { degrees } \\
& \text { reflectance }-80 \%
\end{aligned}
$$

Example 2:

WINDOW

$$
\begin{array}{llll}
1 & .9 & \\
6 . & 5 . & \\
2 & & & \\
4 & 7 & 0 & 3 \\
4 & 19 & 0 & 3 \\
\text { DRAPE } & & \\
.60 & 0 & 2.5
\end{array}
$$

This example defines 2 windows on the south wall; each has clear glazing of $90 \%$ transmittance. Dimensions are $6^{\prime}$ across by $5^{\prime}$ high. Each window runs from $z$-coordinate 3 to 
rev. $11-23-81$

\subsection{FURNITURE block}

This input block is used to define the locations of obstructions in the room; it is always optional in the input deck. The format of the block is:

FURNITURE

$\langle\neq$ obstructions $\rangle$

$\langle I D\rangle\langle x\rangle\langle y\rangle\langle z\rangle \quad\langle$ orientation

repeat for each

obstruction

$\langle I D\rangle\langle x\rangle\langle y\rangle\langle z\rangle \quad\langle o r i e n t a t i o n\rangle$

where

$\langle\neq$ obstructions $>$ is an integer giving the number of obstructions defined in the block. There must be at least one obstruction or the FURNITURE block must be omitted.

$\langle I D\rangle$ is the sequential position (integer value) of the obstruction in the OBSTR database. Refer to the section "Obstructions" for details on the OBSTR database.

$\langle x\rangle\langle y\rangle\langle z\rangle$ are the $(x, y, z)$ coordinates of the exact center of the top face of the obstruction.

<orientation> is the angular displacement (Degrees) between room north and the west face of the obstruction (as the obstruction is defined in the OBSTR database). A positive angle indicates a clockwise displacement; a negative angle indicates a counter-clockwise displacement.

Consider the following example:

3

121.534 .7560

$9825 \quad 590$

$\begin{array}{lllll}4 & 23 & 18 & 4 & -90\end{array}$

Three obstructions are defined:

1) The first obstruction defined in OBSTR is located with its top center at $(21.5,34.75,6)$. Its orientation in the room is the same as its OBSTR orientation.

2) The ninth obstruction defined in OBSTR has its top center located at $(8,25,5)$. In the room, the object has been rotated 90 clockwise (relative to its OBSTR definition).

3) The fourth obstruction defined in OBSTR has its top center located at $(23,18,4)$. In the room, the object has been rotated 


\subsection{DIMMING block}

The DIMMING block is used only with CEL-1 daylight capability. It is optional in "analysis" mode and mandatory in "profile" mode. The format of the block is as follows:

〈Luminaire control method〉

〈luminaire control criterion value (s)>

〈luminaire control indicator

〈control target area definition〉

$\langle\neq$ luminaires always off $\rangle$

$\langle 1$ ist of up to 10 luminaires always off $\rangle$

$\langle$ list of up to 10 luminaires always off $\rangle$

$\langle\neq$ of luminaires in dimming group $\rangle$

$\langle$ list of up to 10 luminaires in the dimming group

〈list of up to 10 luminaires in the dimming group

These input lines are defined as follows:

〈Luminaire control method》 is one of the 6 integers:

$$
-3,-2,-1,1,2 \text {, or } 3
$$

The magnitude of the enrtry defines the controlling

strategy:

1 - luminaires are to be controlled so that at a given time each luminaire is either "on" or "off".

2 - luminaires are to be controlled so that each is in one of three states:

$$
\begin{aligned}
& \text { "high" - full output } \\
& \text { "low" - half output } \\
& \text { "off" - zero output }
\end{aligned}
$$

3 - luminaires are to be controlled so that each controlled luminaire may be continuously dimmed from full output down to some userspecified minimum.

A positive control method indicates that the luminaires are to be dimmed together; i.e., at any given time all controlled luminaires have the same gain. A negative control method means that each controlled luminaire is to be controlled independently from all others. E.g., -3 means continuous dimming, with each luminaire controlled independently; -2 specifies high-low-off control with all luminaires switched as a group. 
rev. $11-23-81$

<luminaire control criterion value $(s)\rangle$ contains 1,2 , or 4 integer values depending on the magnitude of the <luminaire control method selected in the preceding line:

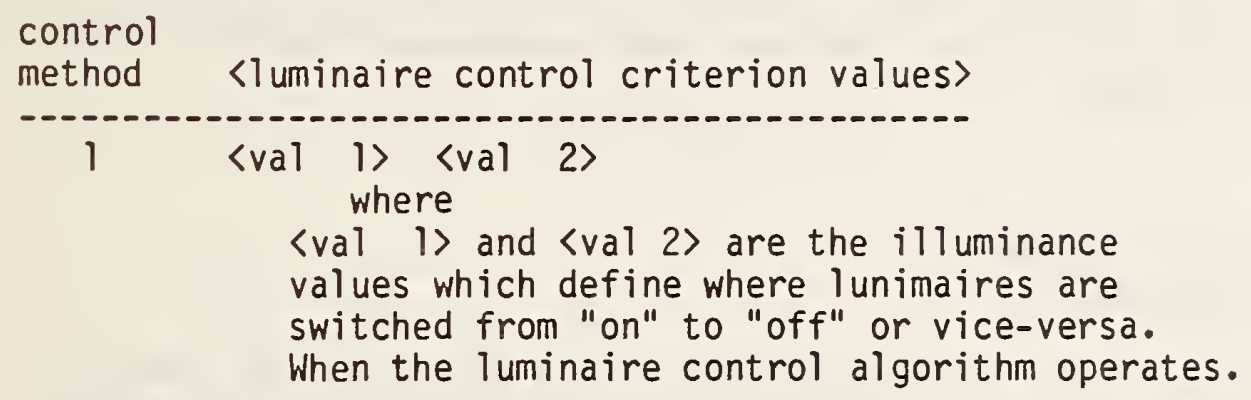


rev. 9-19-83

\subsection{CALCULATE BLOCK}

This input block tells CEL-1 which lighting metrics to calculate. The block takes the following format

CALCULATE

〈keywords〉

〈background BRDF filename〉

〈task BRDF filename〉

where 〈keywords> is a list of 3-character keywords which tell what metrics are to be printed on the output report. The keywords are as follows:

HOR - print horizontal fc (no body shadow)

ESI - print Equivalent Sphere IIluminance (ESI)

RFC - print horizontal fc (incl. body shadow)

TAR - print target luminance

$B A C$ - print background luminance

LEF - print Lighting Effectiveness Factor (LEF)

CRF - print Contrast Rendering Factor (CRF)

VCP - print Visual Comfort Probability (VCP)

PLH - print character contour plots of horizontal fc (no body shadow)

PLE - print character contour plots of ESI, in each viewing direction

PLV - print character contour plots of VCP, in each viewing direction

SUN - print a sketch of the room showing those portions of the task plane which are exposed to direct sunlight at any time during the year. This keyword is used only when the CEL-1 daylight capabilities are exercised.

TDY - print outputs which assist the user in executing the BLAST thermodynamics analysis program. For more details on this output, refer to appendix C.

LUM - print room surface luminance

BLS - request BLAST generator run for CEL-1.1

The keywords may appear on the line in any order; each pair must be separated by exactly one space. The first 


\subsection{Control Cards}

This section shows the card deck structure required to submit the CEL-1 programs to NOS via a remote batch terminal. Submission of the jobs via an interactive terminal is covered in Section VI.

In the discussion to follow the symbolism

\section{$\langle$ data deck〉}

means the cards containing the alphabetic and numeric data which are read in by the CEL-1 programs themselves. The data deck for the CEL-l main program is described in detail in Sections II and III. The input data decks for the auxiliary file maintence programs CCMP and OBMP are described in Section IV. The remaining cards are called "NOS Control Cards" -- they are instructions to the NOS system itself. The "job stream" is the deck of cards obtained by combining the NOS control cards with the input data deck. Here is what the job streams should look like:

\subsection{Job Stream for CEL-1 Main Program}

$\langle$ jobname〉,P4,T500.

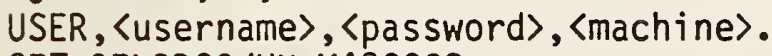

GET, CELPROC $/ U N=M 4800 G S$

CALL, CELPROC.

789 (end of record card)

〈data deck〉

6789 (end of file card)

6.3 Job Stream for Auxiliary Program OBMP

$\langle$ jobname〉,P4, T10.

USER, 〈username〉, 〈password〉, 〈machine〉.

GET, OBMPROC $/ U N=M 4800 G S$

CALL, OBMPROC. 
789 (end of record card)

$$
\langle\text { data deck〉 }
$$

6789 (end of file card)

\title{
6.4 Job Stream for Auxiliary Program CCMP
}

$\langle$ jobname〉,P4,T10.

USER, 〈username〉, 〈password〉, 〈machine〉.

GET, CCMPROC $/ U N=M 4800 G S$

CALL, CCMPROC.

789 (end of record card)

\author{
$\langle$ data deck〉
}

6789 (end of file card)

In the above job streams, each card must be reproduced exactly as shown, except for the entries enclosed in the 〈〉angle brackets, for which the substitutions are:

〈jobname> is 1 to 7 alphanumeric characters which label the user's output. 〈username〉 is the user's NOS account name.

〈password〉 is the user's NOS account password.

〈machine> identifies the NOS machine the user is running on (KWA or KBT)

In addition, the 789 (end of record card) means a card which has rows 7,8 , and 9 punched on column 1. The 6789 (end of file card) has rows $6,7,8$, and 9 punched on column 1 . 


\subsection{Creating the CEL-1 Data Deck using the Preprocessor}

(user logs on)

\section{GETं, CELI FE /UN $=$ M4800GS \\ Ready.}

-Celife

-ENTER 5 LINES OF LABEL INFORMATION, MAX 80 CHARS PER LINE:

? EXAMPLE $1-40^{\circ} \times 30^{\prime} \times 10^{\prime}$ ROOM

? REFLECTANCES: (WALLS $=50 \%$, FLOOR $=20 \%$, CEILING $=80 \%$

? XIX 2-LAMP FLUORESCENT LUMINAIRES (PHOTOMETRIC FILE 'HB57'),

? 3150 LUMENS PER LAMP

? NO FURNITURE OR DAYLIGHT. CALCULATIONS: ESI, HORIZ FC, VCP

- ENTER INPUT UNITS, OUTPUT UNITS ( $1=$ ENGLISH 2=METRIC). ENTER 2 VALUES

? 11

-ENTER FROOM DIMENSIONS, DISCRETIZATION $\neq$ 'S IN PAIRS:

-WIDTH (E-W)

? 4020

-LENGTH (N-S)

? 3015

-HEIGHT

? $\underline{105}$

-ENTER SURFACE REFLECTANCES IN THIS ORDER:

WEST WALL, NORTH WALL, EAST WALL, SOUTH WALL, FLOOR, CEILING

$? .5 .5 .5 .5 .2 .8$

-HOW MANY ROOM SURFACE INSERTS

? $\underline{0}$

-DO YOU WANT TO USE DAYLIGHT (Y/N)

? $\underline{N}$

-HOW MANY OBSTRUCTIONS ARE PRESENT IN THE ROOM

? $\underline{0}$

-IS THIS A DESIGN SYNTHESIZER RUN ( $Y / N)$

?

-DO YOU WANT TO CUMPUTE ESI RATINGS (Y/N)

? N 
-ARE TASK LOCATIONS ON A RECTANGULAR GRID (Y/N)

? Y -ENTER DETAILS FOR GRID OF TASK LOCATIONS:

- $\neq$ COLUMNS (MAX 21)

$? \frac{20}{-\neq}$ ROWS (MAX 21)

? 15

-LEFTMOST $X$-COORDINATE

$? \frac{1}{-R I G H T M O S T} X$-COORDIINATE

? 39

-LOWEST Y-COORDINATE

? 1

-HIGHEST Y-COORDINATE

? 29

-HEIGHT ABOVE FLOOR

? 2.5

-OBSERVER EYE HEIGHT

? 4 .

-HOW MANY VIEWING DIRECTIONS

$? \stackrel{4}{-E}$

-ENTER 4 VIEWING DIRECTION ANGLES

? $0 \quad 90 \quad 180-90$

-WHICH METRICS DO YOU WANT TO PRINT OUT:

-HORIZ FC (NO SHADOW) (Y/N)

? $\frac{Y}{-H O R I Z ~ F C}$ (WITH SHADOW) $(Y / N)$

? N

-ESI $(Y / N)$

? Y

-VCP $(Y / N)$

? $\underline{Y}$

-BACkgROUND LUMINANCE ( $Y / N)$

? $\mathrm{N}$

-TARGET LUMINANCY (Y/N)

? $\mathrm{N}$

-CRF $\quad(Y / N)$

? N

-LEF $\quad(Y / N)$

? $\frac{\mathrm{N}}{-\mathrm{PLOT} \text { HORIZ FC (NO SHADOW) (Y/N) }}$

$\stackrel{N}{-P L O T}$ ESI $\quad(Y / N)$

? $\mathrm{N}$

-PLOT VCP $\quad(Y / N)$

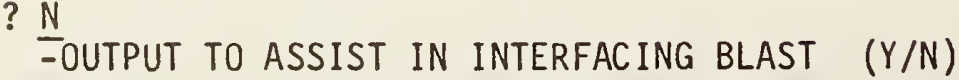

?

-WHAT IS NAME OF FILE WITH BKGD LUMINANCE BRDF FACTORS

? $\underline{\mathrm{P} 25 \mathrm{~B}}$

-WHAT IS NAME OF FILE WITH TASK LUMINANCE BRDF FACTORS 
-ARE TASK LOCATIONS ON A RECTANGULAR GRID (Y/N)

? Y -ENTER DETAILS FOR GRID OF TASK LOCATIONS:

- $\neq$ COLUMNS (MAX 21)

? $\frac{20}{-\neq}$ ROWS (MAX 21)

? 15

-LEFTMOST $X$-COORDINATE

$? \frac{1}{-R I G H T M O S T} X$-COORDIdNATE

? 39

-LOWEST Y-COORDINATE

$?$

-HIGHEST Y-COORDINATE

? 29

-HEIGHT ABOVE FLOOR

? 2.5

-OBSERVER EYE HEIGHT

? 4 .

-HOW MANY VIEWING DIRECTIONS

? 4

-ENTER 4 VIEWING DIRECTION ANGLES

? $0 \quad 90 \quad 180 \quad-90$

-WHICH METRICS DO YOU WANT TO PRINT OUT:

-HORIZ FC (NO SHADOW) ( $/ N$ )

? $\mathrm{Y}$

-HORIZ FC (WITH SHADOW) (Y/N)

? N

-ESI $(Y / N)$

? $\underline{Y}$

$-V C P \quad(Y / N)$

? $\underline{Y}$

-BACKGROUND LUMINANCE (Y/N)

? $\mathrm{N}$ -TARGET LUMINANCY (Y/N)

$\frac{N}{-C R F} \quad(Y / N)$

? $\mathrm{N}$ -LEF (Y/N)

? $\mathrm{N}$ -PLOT HORIZ FC (NO SHADOW) (Y/N)

? $\frac{\mathrm{N}}{-\mathrm{PLOT}}$ ESI $\quad(\mathrm{Y} / \mathrm{N})$

? $\mathrm{N}$ -PLOT VCP $(Y / N)$

? $\mathrm{N}$ -OUTPUT TO ASSIST IN INTERFACING BLAST (Y/N)

? $\underline{\mathrm{N}}$

-WHAT IS NAME OF FILE WITH BKGD LUMINANCE BRDF FACTORS

? $\underline{\mathrm{P} 25 \mathrm{~B}}$

-WHAT IS NAME OF FILE WITH TASK LUMINANCE BRDF FACTORS

? P25T 
- HOW MANY DIFFERENT TYPES OF LUMINAIRES DO YOU INTEND TO USE ? 1

-FOR LUMINAIRE TYPE $\neq \quad 1$ : -WHAT IS PHOTOMETRIC FILE NAME

? HB57

-TOTAL INITIAL LAMP LUMENS

? 6300

-LIGHT LOSS FACTOR

?.82

-WIDTH OF LUMINOUS OPENING

? 1.833

-LENGTH OF LUMINOUS OPENING

? 3.833

-HEIGHT OF LUMINAIRE

$? .5$

-FOR EACH LUMINAIRE ENTER $X, Y, Z$ COORDINATES AFTER " $(X, Y, Z) "$ PROMPT? ENTER BEARING, TILT, CANT AFTER "ORIENT" PROMPT.

$-\operatorname{LUM} \neq \quad 1:$

$(X, Y, Z)$

$? \frac{10109.5}{0 R 1 E N T}$

ORIENT

? 0000

- LUM $\neq 2:$

$(X, Y, Z)$

? $20 \quad 109.5$

? 000

- LUM $\neq \quad 3:$

$(X, Y, Z)$

? $\frac{30109.5}{\text { ORIENT }}$

? 000

- LUM $\neq 4:$

$(X, Y, Z)$

? 10209.5

ORIENT

? 0000

- LUM $\neq 5:$

$(X, Y, Z)$

? 20209.5 ORIENT

? 0

- LUM $\neq 6:$

$(X, Y, Z)$

? $30 \quad 209.5$ ORIENT

? 000 
rev. $11-23-81$

$-162.1-$

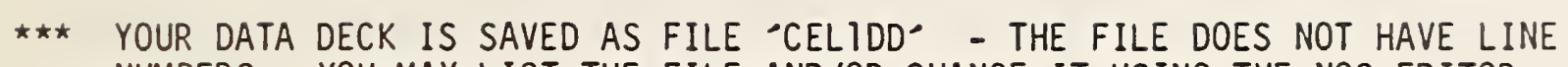
NUMBERS. YOU MAY LIST THE FILE AND/OR CHANGE IT USING THE NOS EDITOR. TO SUBMIT THE DECK FOR EXECUTION, KEY IN:

GET, CELIII /UN=M4800GS

-CELIII 
7.6 Submitting the Job to NOS for Execution

(user logs on, then creates the data deck file using an NOS editor. The data deck file for CELI (CELIDD) may al so be created using the preprocessor. CELIFE)

GET, CELTII/UN=M4800GS

READY,

-CELTII

-- CEL-1 INTERACTIVE INTERFACE --

-ENTER ID OF PROGRAM YOU WANT TO RUN:

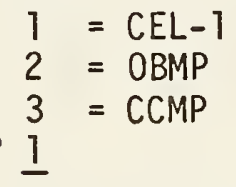

-ENTER PRIORITY FOR JOB $(1,2,3,4$, OR 6$)$

? $\underline{2}$

-LOCATION CODES ARE:

$F$ NAVFAC

L LANTDIV

$S$ SOUTHDIV

$P$ PACDIV

$W$ WESTDIV

$N$ NORTHDIV

H CEL, PORT HUENEME

C CHESDIV

-ENTER YOUR LOCATION CODE

? $\mathrm{H}$

-ENTER CODE FOR DISPOSITION OF OUTPUT:

1 ROUTE TO YOUR REMOTE BATCH TERMINAL

2 PRINT AT CENTRAL SITE, MAIL TO YOU

3 SAVE FOR SUBSEQUENT RETRIEVAL AT INTERACTIVE TERMINAL

? 1

-ENTER YOUR FIRST NAME (MAX 10 CHARS)

? $\underline{B I L L}$ 
rev. $11-23-81$

$-165.1-$

-IDENTIFY YOUR FAMILY NAME (1 OR 2):

$1=$ KWA

$2=K B T$

?'1

-DOES FILE 'CELIDD' HAVE LINE NUMBERS ( $Y / N)$

? $\underline{N}$

-DO YOU WANT TO SUBMIT THIS JOB (Y/N)

$? \frac{Y}{19} .56 .56$. A2MOKHE READY.

Use these three letters to query the job status with the command

ENQUIRE, JN=KHE 
FUNITURE BLOCK:

FURNITURE

\section{\#OBSTRUCTIONS}

database ID $X$ Y $\quad Y$ Z orientation

(repeat above card for each different obstruction)

PROFILE BLOCK: (inlcuded only when computing energy profile and requesting BLAST generator run)

PROFILE

\begin{tabular}{cccc}
\hline Tat. Tong. Tong. at center station date of & date of & date of \\
of time zone & ID & 1st sat. & $1^{\text {st }}$ day last day
\end{tabular}

daylight savings time map

occupancy factors

ANALYSIS BLOCK:

ANALYSIS

\begin{tabular}{ccc}
\hline Tatitude longitude & $\begin{array}{c}\text { Tongitude at center } \\
\text { of time zone }\end{array}$ & station \\
ID
\end{tabular}

daylight savings time map

\# times (maximum 15)

month day time of day

(repeat above card for each time) 
APPENDIX A - COMMON Block Variable Definitions

\section{A-1 Common Block /COBAS/}

This common block is the "basic" block in that it contains variables used by virtually all the programs.

ROOMD - the $x, y$, and $z$ dimensions of the room

TORG - the $(x, y, z)$ coordinates of the point on a rectangular grid of target points which is nearest the origin

VIEW - the viewing directions for a rectangular grid of target points

RHO - the reflectance of the six room surfaces

WATTS - the watts consumption per luminaire at 100 percent gain

SQUAD - quadratic coefficients giving watts vs. gain

GMIN - minimum gain to which a luminaire can be dimmed

LORG - the point on a rectangular grid of luminaires which is nearest the origin (used only in design synthesizer)

NDIV - \# of discrete zones into which the room surfaces are divided - in order, $x, y$, and $z$ directions

INDC - 15 binary indicators governing which quantities are to be computer/ printed:

1 - horizontal illumination

2 - ESI

3 - raw illum. w/body shadow

4 - LEF

5 - CRF

6 - target luminance

7 - background illuminance

8 - VCP
9 - plot horiziontal illum.

10 - plot ESI

11 - plot VCP

12 - Sun trace in room

13 - BLAST interface output

14 - room surface luminances

15 - BLS (BLAST generator run)

DESC - 5 lines of descriptive text to label output

DOESI - $(0=$ don't compute ESI, $1=$ do compute ESI) Equivalenced to INDC (2)

OUNITS - output units ( $1=$ English, $2=$ metric)

IUNITS - input units ( $1=$ English, $2=$ metric)

IKNOWN - 1 = ESI Ratings to be computed at task locations, 2 = UNKNOWN task locations (rectangular grid), 3 = KNOWN task locations

NTC - \# columns of target points (UNKNOWN task locations)

NTR - " rows of target points (UNKNOWN task locations)

DCT - grid column space (UNKNOWN task locations)

DRT - grid row spacing (UNKNOWN task locations)

NV - \# viewing directions

NFTYPE - \# fenestration sub-blocks actually describing fenestrations

NWIND - \# fenestration source elements (windows, skylights, etc.)

NSURF - \# exterior building surfaces + \# ground surfaces

NTASKL - \# task locations

NTP - \# target points

NFOTO - \# different photometric files used

GREF - reflectance of ground

NINS - \# of room surface inserts

IOP - 1 ESI Rating at IES viewing directions, 2 ESI Rating at Navy viewing directions

NEWP $-=\operatorname{NDIV}(1)=\#$ discrete room zones in $x$-direction 
NBS-1 ? 4 A (REV. 2-8C)

U.S. DEPT. OF COMM.

1. PUBLICATION OR

BIBLIOGRAPHIC DATA

SHEET (See instructions) REPORT NO.

4. TITLE AND SUBTITLE

CEL-1 User's Guide Update

5. $A U T H O R(S)$

Stephen J. Treado, Cynthia L. Francisco and Douglas B. Holland

\begin{tabular}{l|l} 
6. PERFORMING ORGANIZATION (If joint or other thon NBS, see instructions) & 7. Contract Grant No.
\end{tabular}

NATIONAL BUREAU OF STANDARDS

DEPARTMENT OF COMMERCE

8. Type of Report \& Period Covered

WASHINGTON, D.C. 20234

9. SPONSORING ORGANIZATION NAME AND COMPLETE ADDRESS (Street, City, StOte, ZIP)

10. SUPPLEMENTARY NOTES

[ Document describes a computer program; SF-185, FIPS Software Summary, is attached.

11. ABSTRACT (A 200-word or less factual summary of most significant information. If document includes a significant bibliography or literature survey. mention it here)

This is a guide to using the CEL-1.1 version of the CEL-1 Lighting Computer Program. CEL-1.1 has the capability of producing hour-by-hour lighting power multipliers for a one-year simulation period. This guide focuses on:

a) the new program routines

b) the interactive capabilities of CEL-1.1

c) the routines for compiling different types of routines

d) computer terminology and accessing the necessary routines for running CEL-1. 1

e) updates and revisions to the existing CEL-1 manuals.

12. KEY WORDS (Six to twelve entries; alphabetical order; capitalize only proper names; and separate key words by semicolons) BIAST generator; cloud ratio; direct and diffuse illuminance; direct and diffuse irradiance; lighting power multipliers.

13. AVAILABILITY

AVAI

Unlimited

$\square$ For Official Distribution. Do Not Release to NTIS

$\square$ Order From Superintendent of Documents, U.S. Government Printing Office, Washington, D.C. 20402.

$\square$ Order From National Technical Information Service (NTIS), Springfield, VA. 22161

14. NO. OF

PRINTED PAGES

71

15. Price

$\$ 10.00$ 

